\title{
Bone metastases from differentiated thyroid carcinoma: current knowledge and open issues
}

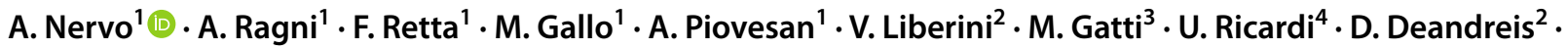 \\ E. Arvat ${ }^{1}$
}

Received: 1 May 2020 / Accepted: 24 July 2020 / Published online: 3 August 2020

(c) The Author(s) 2020

\begin{abstract}
Bone represents the second most common site of distant metastases in differentiated thyroid cancer (DTC). The clinical course of DTC patients with bone metastases (BM) is quite heterogeneous, but generally associated with low survival rates. Skeletal-related events might be a serious complication of BM, resulting in high morbidity and impaired quality of life. To achieve disease control and symptoms relief, multimodal treatment is generally required: radioiodine therapy, local procedures-including surgery, radiotherapy and percutaneous techniques-and systemic therapies, such as kinase inhibitors and antiresorptive drugs. The management of DTC with BM is challenging: a careful evaluation and a personalized approach are essential to improve patients' outcomes. To date, prospective studies focusing on the main clinical aspects of DTC with BM are scarce; available analyses mainly include cohorts assembled over multiple decades, small samples sizes and data about BM not always separated from those regarding other distant metastases. The aim of this review is to summarize the most recent evidences and the unsolved questions regarding BM in DTC, analyzing several key issues: pathophysiology, prognostic factors, role of anatomic and functional imaging, and clinical management.
\end{abstract}

Keywords Thyroid cancer $\cdot$ Skeletal-related event $\cdot$ Metastatic disease $\cdot$ Cancer management

\section{Introduction}

Although differentiated thyroid carcinoma (DTC) accounts for only $3 \%$ of all reported malignancies [1], it is one of the five types of cancer that most frequently cause bone

A. Nervo

alice.nervo@gmail.com

A. Ragni

alberto.ragni@edu.unito.it

F. Retta

fra.retta@gmail.com

M. Gallo

mgallo4@cittadellasalute.to.it

\section{A. Piovesan}

apiovesan@cittadellasalute.to.it

V. Liberini

virginia.liberini@unito.it

M. Gatti

marcogatti17@gmail.com

U. Ricardi

umberto.ricardi@unito.it metastases (BM) [2]. In DTC population, BM occurs in $2-13 \%$ of all cases and can be detected in nearly half of the patients with distant metastases. After the lung, the skeleton is the second most common site of distant metastases in DTC [3, 4]. BM from DTC are generally osteolytic lesions
D. Deandreis

desiree.deandreis@unito.it

E. Arvat

emanuela.arvat@unito.it

1 Oncological Endocrinology Unit, Department of Medical Sciences, Città della Salute e della Scienza Hospital, University of Turin, Turin, Italy

2 Nuclear Medicine, Department of Medical Sciences, Città della Salute e della Scienza Hospital, University of Turin, Turin, Italy

3 Radiology Unit, Department of Surgical Sciences, Città della Salute e della Scienza Hospital, University of Turin, Turin, Italy

4 Radiation Oncology, Department of Oncology, Città della Salute e della Scienza Hospital, University of Turin, Turin, Italy 
with secondary bone formation in response to bone destruction and soft tissue involvement [4].

Any type of DTC can metastasize to bone structures. The rate of $\mathrm{BM}$ is threefold higher for follicular thyroid cancer (FTC, 7-28\%) compared with papillary thyroid cancer (PTC, 1-7\%) [5]. A likely explanation is that FTC more easily spreads via the blood stream to distant organs, due to a major tendency to invade blood vessels [6].

Axial skeleton, especially the spine and the pelvis, is the most common involved site. Cancer cells easily reach the red marrow of these bone segments since blood inflow is notoriously high. Furthermore, a preferential link between the thyroid gland and the axial skeleton is provided by Batson's vertebral-venous plexus, which plays a role in the drainage of the head and neck region by indirect connections with the inferior thyroid veins [7].

Skeletal-related events (SREs), which include pathologic fractures, spinal cord compression, need for bone irradiation or surgery and malignant hypercalcemia, might be a serious complication of BM in DTC patients, resulting in quality of life impairment and high morbidity. Farooki et al. reported a 78\% occurrence of SREs in DTC patients with BM; after a median of 10.7 months, $65 \%$ of them sustained a second SRE [8].

Prognosis of DTC patients with BM is generally poor and survival rates are lower than those observed with localisations at other distant sites $[3,9]$ : the overall survival (OS) at 10 years ranges from 13 to $21 \%$ [4].

\section{Pathophysiology}

In recent years, the mechanisms underlying the development of BM from different types of cancer have been widely investigated.

The tumour-induced disregulation of the RANK-RANK ligand-osteoprotegerin pathway seems to be common to all osteolytic malignancies: activation of RANK leads to recruitment and maturation of osteoclasts, which directly influence the resorption of bone. In case of BM from DTC, how this process is altered is still unknown [10].

The loss of physiologic cell-cell and cell-matrix interactions is essential for cancer cells to acquire the ability to invade distant sites, including bones. Being a highly vascularised organ, the skeleton is a favourable target for haematogenous invasion: cancer cells are transported by the blood flow and, through specific cell adhesion molecules, are able to bind marrow stromal cells and bone matrix [10]. According to the "seed and soil" hypothesis, metastases will develop only in the presence of a favourable microenvironment. Bone is a large repository for growth factors (e.g. insulin-like growth factor, fibroblast growth factor and platelet-derived growth factor), which are released during bone resorption and promote bone homing, colonization, and subsequent tumour growth, as depicted in Fig. 1 [6].

Fibronectin, which normally suppresses cellular migration and adhesion, has been found to be downregulated in FTC cells [10]. Conversely, focal adhesion kinase, which
Fig. 1 The main mechanisms underlying the development of BM. $B M$ bone metastases, $F G F$ fibroblast growth factor, $I G F$ insulin-like growth factor, $P D G F$ platelet-derived growth factor, $R A N K$ receptor activator of nuclear factor $\mathrm{K} \mathrm{B}, R A N K L$ RANK ligand, $O P G$ osteoprotegerin

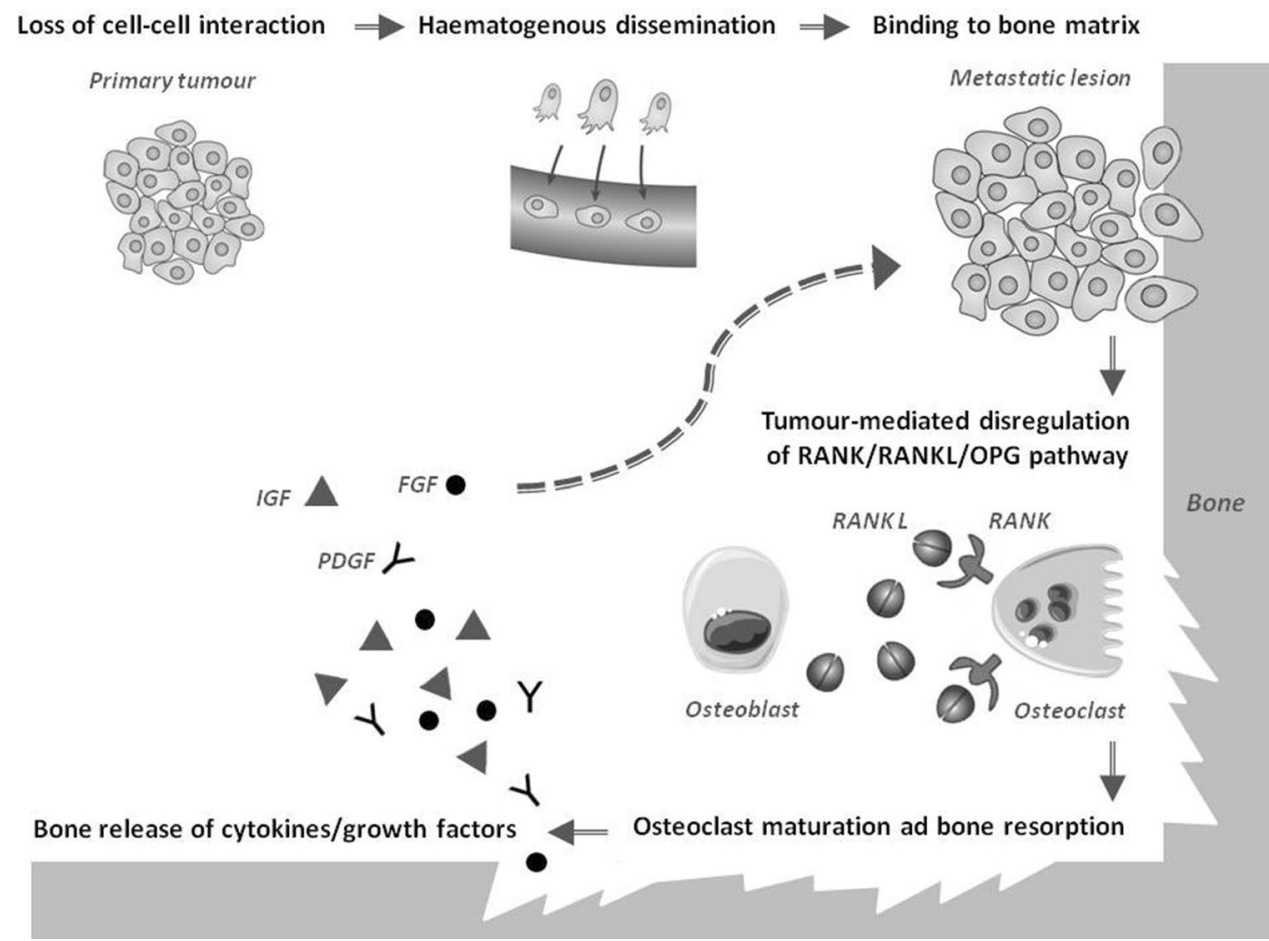


promotes tumour invasion, was highly expressed in aggressive thyroid cancers. Interestingly, overexpression of bone sialoprotein and integrin $\alpha v \beta 3$ in thyroid cancer cells seems to increase bone adhesion and osteolysis. Also, the different expression of the tumour suppressor genes caveolin-1 and caveolin-2, upregulated in FTC and downregulated in PTC, has been hypothesized to explain the higher propensity of FTC to metastasize to bones when compared to PTC [4]. Nevertheless, a whole understanding of the molecular mechanisms involved in the development of BM in DTC is still lacking.

\section{Prognostic factors}

Site, clinical presentation, and burden of metastases are important prognostic factors for DTC, together with age at diagnosis, histological subtype, radioactive iodine (RAI), and ${ }^{18} \mathrm{~F}$-fluorodeoxyglucose $\left({ }^{18} \mathrm{~F}\right.$-FDG) avidity [11].

DTC patients with BM generally show a poor prognosis; however, their clinical course may be quite heterogeneous. Asymptomatic patients with RAI-avid BM, but no structural evidence of disease on high-resolution imaging studies, demonstrate excellent responses and better survival [12]. Various retrospective studies tried to identify factors able to independently predict the natural course of DTC patients with BM [13-16]. Nevertheless, many of them lead to inconclusive results, since cohorts were often assembled over multiple decades during which both histopathological evaluation and clinical management have evolved. In several cases, the sample size was very limited to perform meaningful multivariate analyses. Moreover, data about BM were not always separated from those regarding other distant metastases [2].

Nevertheless, at multivariate analysis, the coexistence of non-bone metastases resulted to be an unfavourable prognostic variable in different studies $[13,14]$, while younger age and extra-spinal BM were found to be independent predictors for improved survival [15]. Patients with RAI-avid BM showed a better outcome when compared to subjects with non-RAI avid BM. This finding is somewhat expected, since RAI avidity implies a better differentiation of the tumour itself and a higher efficacy of RAI therapy [3, 13].

A recent study demonstrated that the timing of BM detection could predict survival: a worse prognosis was observed in case of BM detected at the moment of DTC diagnosis, rather than at the moment of the first RAI treatment or during follow-up [16]. A possible explanation of this finding is that patients with BM at diagnosis are likely to have discovered a metastatic DTC following a SRE, while patients with BM detected by RAI therapy often have lesions with no structural correlation. In the same study, the histopathological subtype (PTC or FTC) did not seem to significantly influence the prognosis, even if there was a significantly higher number of patients with FTC in the group with poorer prognosis [16]. In other studies regarding DTC patients with BM, aggressive histotypes (i.e. tall cell, columnar cell, hobnail and insular variants) were associated with a higher risk of disease progression [15], mortality and SREs [17], albeit these findings were not confirmed at multivariate analysis.

\section{The role of anatomic and functional imaging}

\section{Diagnostic role}

BM from DTC are mainly of lytic type and can be frequently associated to an extension into surrounding soft tissues [4]. Plain radiograph is not useful in early detection of small osteolytic lesions, indeed, extensive (30-50\%) bone mineral loss is required before it becomes radiographically visible, in particular for the spine and the pelvis. On the other hand, plain radiographs are indicated as first-line imaging study in patients with bone pain or abnormal absorption of radionuclides to exclude a pathological fracture [18]. Computed tomography (CT) and magnetic resonance imaging (MRI) allow to better characterize BM thanks to a higher resolution and a three-dimensional anatomic information (Fig. 2). CT is helpful in visualizing the extension of the lesion and the cortical integrity, also allowing an easy characterization of the lesions as lytic or sclerotic. The sensitivity and specificity reported are 74 and 56\%, respectively [19]. Moreover, CT can also be employed for an image-guided bone biopsy. MRI can detect very small BM contributing to an earlier detection of the lesions. The diagnostic accuracy proved to be significantly superior to 16/64-row-slice multidetector CT [20]. Furthermore, in case of vertebral metastases, MRI is essential for the assessment of epidural, nerve, and spinal cord involvement, playing a pivotal role in the pre-surgical workup [21, 22]. Whole-body (WB) MRI with diffusionweighted imaging (MRI-DWI) is a promising imaging technique in the evaluation of $\mathrm{BM}$ from different solid tumours, including DTC [23]. The added value of DWI is the addiction of functional information to morphological sequences: being able to detect differences in cellularity of malignant bone marrow disorders with respect to the normal bone marrow, it might help in differentiating between malignant and benign lesions. WB-MRI-DWI showed a higher sensitivity in the detection of BM from DTC when compared to WBMRI with standard protocol (82 vs $64 \%$ ) and similar to ${ }^{18} \mathrm{~F}$ FDG positron emission tomography (PET)/CT (79\%) [24]. Conversely, in another study involving patients with metastatic DTC, WB-MRI-DWI showed a lower detectability rate (76.5\%) for BM comparing to ${ }^{18} \mathrm{~F}$-FDG PET/CT $(85.7 \%)$; both techniques were indicators of poor prognosis [25]. A new MRI perfusion technique (dynamic contrast-enhanced, 

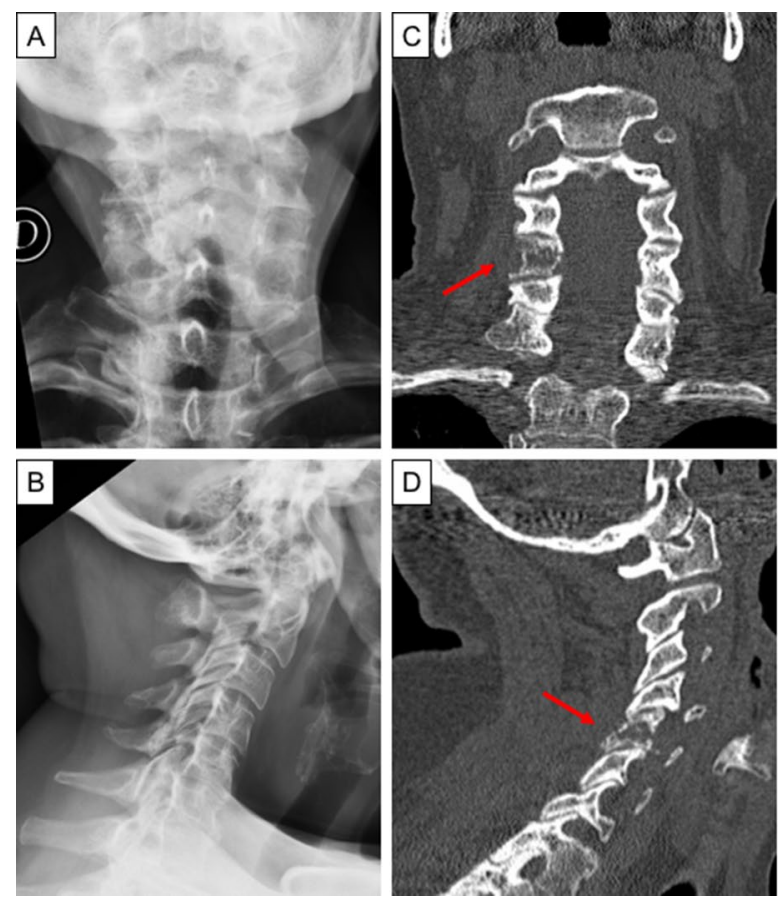
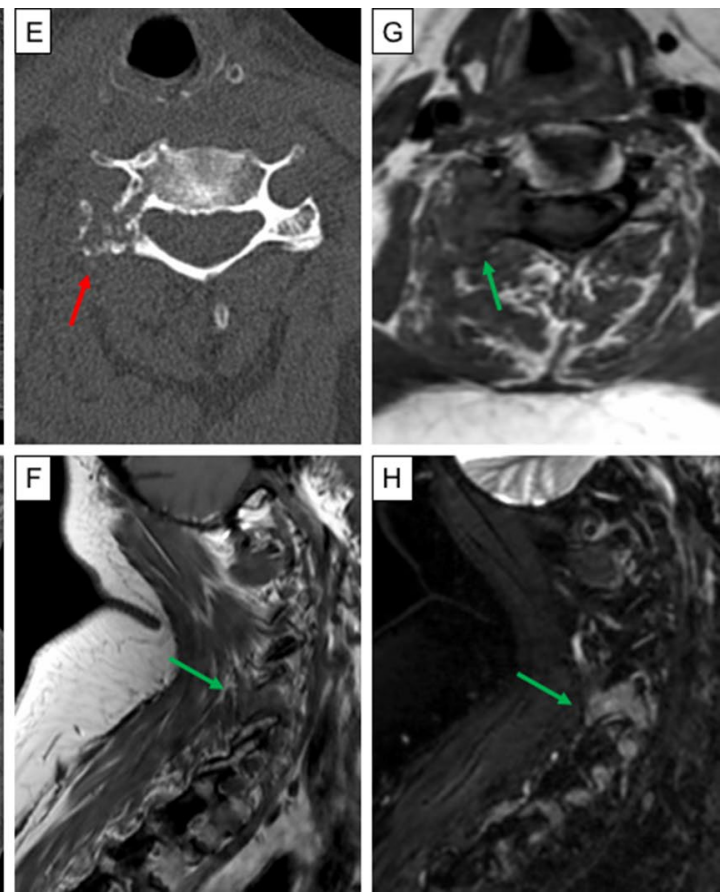

Fig. 2 Images from a 55-year-old female with poorly differentiated thyroid cancer and cervical pain. The patient underwent cervical spine plain radiograph (a postero-anterior view, b latero-lateral view) that was reported as negative. Therefore, after a few days, she underwent cervical spine CT. The CT multiplanar reconstructions images (c axial view, d coronal view, e sagittal view) showed the presence of an osteolytic bone lesion involving the peduncle and the zygapo-

DCE) has recently been investigated in the diagnostic workup of spinal metastases, showing the ability to detect early vertebral body infiltration and tumour vascularity [26]. The latter characteristic might allow DCE-MRI to become an imaging modality for the evaluation of the response to antiangiogenic therapies. Further investigations need to be carried out, especially in DTC setting, to confirm this hypothesis [27].

Among nuclear medicine functional imaging techniques, WB ${ }^{131}$ iodine $\left({ }^{131} \mathrm{I}\right)$ scintigraphy is traditionally performed following the administration of RAI therapy: it allows to identify RAI-avid lesions and, in this setting, is more sensitive than ${ }^{18} \mathrm{~F}$-FDG PET/CT in the identification of BM [28]. However, planar ${ }^{131} \mathrm{I}$ ( or ${ }^{123} \mathrm{I}$ ) WB imaging has limited spatial resolution, which can result in inaccurate localisation and characterization of RAI uptake. By acquiring data in three dimensions, single-photon emission computed tomography (SPECT) imaging enables a more precise differentiation between physiologic uptake and metastatic lesions. The improved accuracy in the characterization of foci of increased tracer uptake emerges especially when functional and structural data are combined in a single imaging session by hybrid imaging (SPECT/CT). In DTC patients with $\mathrm{BM}, \mathrm{SPECT} / \mathrm{CT}$ is superior for the precise localisation physeal joint with minimal involvement of the hemisoma of the fifth cervical vertebra (red arrow). The MR images (f T1-weighted sagittal view; $\mathbf{g}$ T1-weighted axial view; $\mathbf{h}$ T2-weighted with fat suppression sagittal view) confirmed the CT scan findings, with a lesion which resulted hypointense in $\mathrm{T} 1$ and hypertense in T2 (green arrow). $C T$ computed tomography, $M R$ magnetic resonance

and assessment of the extent of bone involvement [29, 30]. Moreover, the CT component of SPECT/CT might also detect non-RAI avid lesions [29, 31].

${ }^{18}$ F-FDG PET/CT showed good sensitivity and specificity for the identification of local recurrences or metastases in DTC patients with increased serum Tg levels and negative WB ${ }^{131}$ I scan according to the "flip-flop phenomenon" $[32,33]$. The administration of recombinant human TSH (rhTSH) prior to ${ }^{18} \mathrm{~F}-\mathrm{FDG}$ PET/CT imaging in DTC patients with $\mathrm{BM}$ did not seem to provide any significant additional information with an increased risk of false positive findings [34]. ${ }^{18} \mathrm{~F}-\mathrm{FDG}$ PET/CT could also provide prognostic information: reduction of OS was observed for PET-positive versus PET-negative BM [28].

Some controversies emerged when comparing ${ }^{18} \mathrm{~F}-\mathrm{FDG}$ PET/CT and ${ }^{99 \mathrm{~m}}$ Technetium-methylene diphosphonate-planar bone scintigraphy $\left({ }^{99 \mathrm{~m}} \mathrm{Tc}-\mathrm{MDP}-\mathrm{BS}\right)$ for the detection of BM from different cancer types [35]. In DTC with BM, the accuracy of ${ }^{18} \mathrm{~F}$-FDG PET/CT is significantly higher than that of ${ }^{99 \mathrm{~m}} \mathrm{Tc}-\mathrm{MDP}-\mathrm{BS}[28,36]$. This is due to ${ }^{18} \mathrm{~F}$-FDG $\mathrm{PET} / \mathrm{CT}$ ability to detect the presence of the tumour directly by its metabolic activity and glucose uptake into cancer cells and, therefore, it might detect BM at an earlier stage [28]. ${ }^{99 \mathrm{~m}} \mathrm{Tc}-\mathrm{MDP}$ uptake depends on osteoblastic bone reaction to 
cancer cells, but, as previously described, the lytic nature of BM from DTC limits bone scan accuracy [28].

The role of PET/CT with the bone-seeking radiotracer ${ }^{18}$ fluorine-labeled sodium fluoride $\left({ }^{18} \mathrm{~F}-\mathrm{NaF}\right)$ has been studied in few cases of BM from DTC and compared to ${ }^{18} \mathrm{~F}$ FDG. ${ }^{18} \mathrm{~F}$-FDG PET/CT showed a lower sensitivity in the detection of osteoblastic lesions in comparison to ${ }^{18} \mathrm{~F}-\mathrm{NaF}$ $\mathrm{PET} / \mathrm{CT}$, but was more sensitive in evaluating bone marrow involvement and early bone lesions [37-39]. The use of ${ }^{18} \mathrm{~F}-$ $\mathrm{NaF}$ PET in clinical practice should be further evaluated.

The use of ${ }^{68}$ Gallium $\left({ }^{68} \mathrm{Ga}\right)$ DOTATATE as a radiotracer for PET/CT has also been investigated in RAI-refractory metastatic DTC. However, a study focused on its detection rate of BM from DTC and a direct comparison with other functional imaging techniques is still lacking [40]. Another ${ }^{68} \mathrm{Ga}$-labeled radiotracer $\left({ }^{68} \mathrm{Ga}\right.$-DOTA-RGD2), an angiogenic marker, has been studied in RAI-refractory DTC patients showing similar accuracy in detecting BM, albeit in a small sized cohort [41].

Compared to anatomical imaging techniques, all functional techniques share the advantage of providing a whole body assessment that is extremely favorable for disease staging (Fig. 3).

The main strengths and limits of the imaging techniques most frequently used in the detection of BM in DTC patients are summarized in Table 1.

\section{Predictive role}

In recent years, an important role of kinase inhibitors (KIs) for the management of RAI-refractory DTC has emerged. The radiological assessment of response to these agents becomes particularly challenging in presence of BM. Response evaluation criteria in solid tumours (RECIST)
1.1 are commonly employed for the evaluation of response to therapy with KIs in cancer patients, including DTC [42, 43]. However, BM without soft tissue involvement measuring $\geq 10 \mathrm{~mm}$-representing the large majority of $\mathrm{BM}$-are designated as unmeasurable, only a frank progression of BM can classify the patient response as unequivocal progression [44].

Bone-specific response criteria were developed at the University of Texas MD Anderson Cancer Center and can be useful in patients with bone-only metastases (MDA criteria). This system allows a greater percentage of BM to be considered measurable disease. Moreover, it takes into account the development of healing sclerosis: visualization of sclerotic lesions or lytic lesions with sclerotic rims might not indicate disease progression (PD) but the healing of previously inconspicuous lesions. Clearly, the so-called osteoblastic flare phenomenon cannot be diagnosed if signs of PD (i.e. appearance or enlargement of other lytic lesions) are detected in other sites [45]. Also bone scintigraphy, as reported in other cancer types such as breast and prostate cancer, can detect flare effect which occurs when healing sclerosis results in an increased bone tracer uptake (or also in the appearance of new osteoblastic lesions), typically within the first 3 months after therapy. In this case, the combination of clinical information, the use of other imaging studies (CT/MRI), and the evolution on sequential imaging are essential for a correct interpretation of the scan findings [39]. However, no focused evaluation of the BM response to systemic therapy in DTC patients according to these criteria is currently available, to our knowledge.

Being cytostatic drugs, KIs might not always determine a profound change in tumour size despite their effectiveness. Therefore, morphologic-based criteria could not detect the actual tumour response and fail to demonstrate the real
Fig. 3 Pre-operatory staging with 18F-FDG PET/CT scan of a 63-year-old female with a lytic lesion of the iliac bone seen at a plain radiograph of the pelvis and subsequently subjected to bone biopsy with histological diagnosis of FTC metastasis. 18F-FDG PET-CT images show the thyroid lesion (a) and three bone metastasis involving a rib (b), the sternum (c) and the iliac wing (d). 18F-FDG PET/ $C T$ 18F-fluorodeoxyglucose positron emission tomography/ computed tomography, FTC follicular thyroid cancer
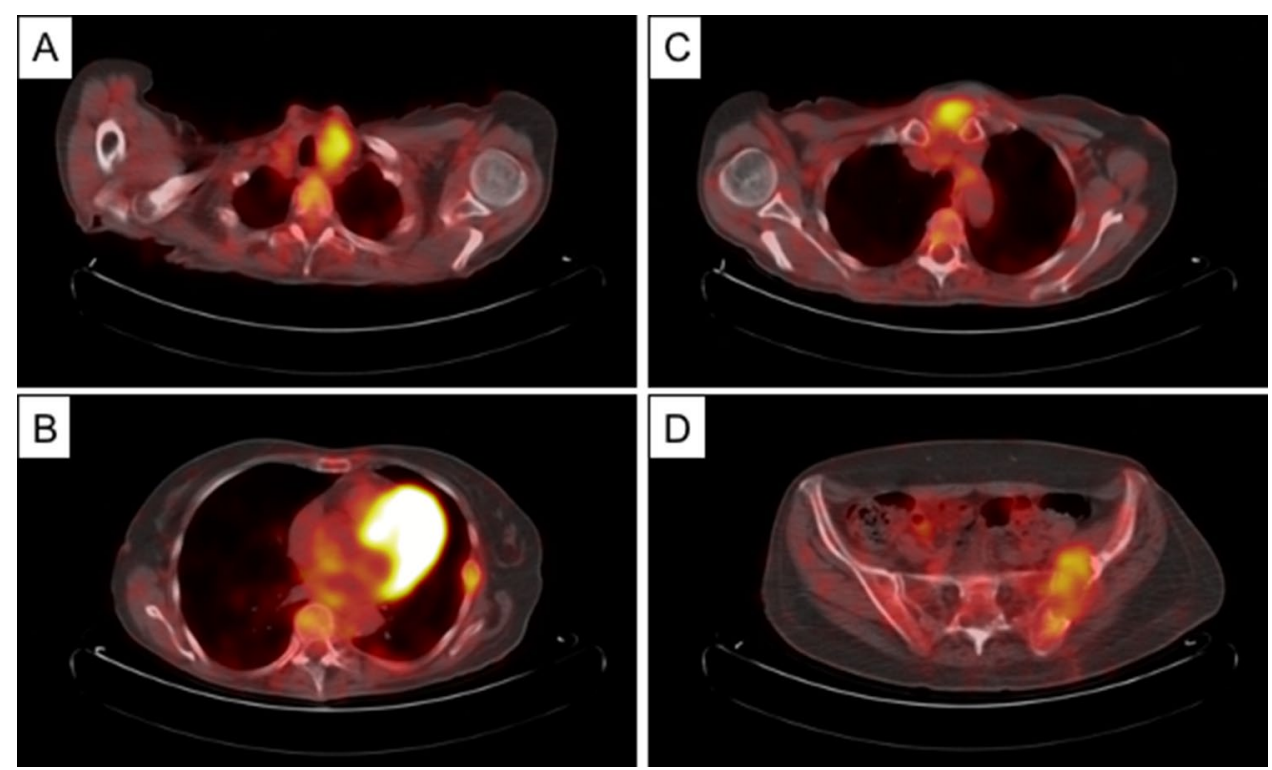
Table 1 Strengths and limits of the main imaging modalities used for the detection of BM in DTC patients

\begin{tabular}{|c|c|c|}
\hline Imaging technique & Strengths & Limits \\
\hline Plain radiograph & $\begin{array}{l}\text { Diffuse availability } \\
\text { Low costs } \\
\text { Assessment of potential pathological fractures }\end{array}$ & $\begin{array}{l}\text { Low sensitivity } \\
\text { Incapacity of detecting soft tissue involvement }\end{array}$ \\
\hline $\mathrm{CT}$ & $\begin{array}{l}\text { High resolution and three-dimensional information } \\
\text { Lesion characterization } \\
\text { Assessment of cortical integrity } \\
\text { Guidance for bone biopsy }\end{array}$ & Intermediate sensitivity \\
\hline MRI & $\begin{array}{l}\text { High sensitivity } \\
\text { Assessment of soft tissue and neural structures involvement } \\
\text { Possibility of employment of functional techniques (DWI, } \\
\text { DCE) }\end{array}$ & $\begin{array}{l}\text { High costs } \\
\text { Longer scan times } \\
\text { Contraindicated in presence of implantable devices }\end{array}$ \\
\hline${ }^{131}$ I scintigraphy & $\begin{array}{l}\text { High sensitivity for RAI-avid lesions } \\
\text { Whole body assessment } \\
\text { Theranostic value }\end{array}$ & $\begin{array}{l}\text { Limited spatial resolution (improved by SPECT/CT) } \\
\text { Limited value in case of non RAI-avid lesions }\end{array}$ \\
\hline Bone scintigraphy & Whole body assessment & $\begin{array}{l}\text { Limited spatial resolution (improved by SPECT/CT) } \\
\text { Limited accuracy in detecting lytic lesions }\end{array}$ \\
\hline${ }^{18} \mathrm{~F}-\mathrm{FDG}$ PET/CT & $\begin{array}{l}\text { Whole body assessment } \\
\text { High sensitivity in non-RAI-avid lesions } \\
\text { Prognostic value }\end{array}$ & $\begin{array}{l}\text { Lower sensitivity than }{ }^{131} \text { I scintigraphy for RAI-avid lesions } \\
\text { Lower anatomical assessment accuracy than high-resolution } \\
\text { CT }\end{array}$ \\
\hline${ }^{18} \mathrm{~F}-\mathrm{NaF}$ PET/CT & $\begin{array}{l}\text { Whole body assessment } \\
\text { Higher sensitivity than }{ }^{18} \text { F-FDG PET/CT in detecting osteo- } \\
\text { blastic lesions }\end{array}$ & $\begin{array}{l}\text { Lower sensitivity than }{ }^{18} \mathrm{~F}-\mathrm{FDG} \text { PET/CT in evaluating bone } \\
\text { marrow involvement and early bone lesions } \\
\text { Low availability } \\
\text { Low clinical experience }\end{array}$ \\
\hline
\end{tabular}

$C T$ computed tomography, MRI magnetic resonance imaging, $D W I$ diffusion-weighted imaging, $D C E$ dynamic contrast enhanced, ${ }^{131} I^{131}$ iodine, $R A I$ radioactive iodine, SPECT single-photon emission computed tomography, PET positron emission tomography, ${ }^{18} F-F D G{ }^{18}$ fluorine-fluorodeoxyglucose, ${ }^{18} \mathrm{~F}-\mathrm{NaF}{ }^{18}$ fluorine-sodium fluoride

clinical benefit. ${ }^{18}$ F-FDG PET/CT scan can be a useful method to measure metabolic response of ${ }^{18} \mathrm{~F}$-FDG-avid BM [45]. Positron emission tomography response criteria in solid tumours (PERCIST) have been proposed to measure disease response through the assessment of metabolic activity variation. Although they are employed in clinical trials, their use in real-life practice is not usual [46].

Recently, early metabolic assessment in apatinib-treated RAI-refractory DTC has been investigated [47]. However, the role of functional imaging and its correct timing need to be further explored along with anatomic criteria for the evaluation of BM changes during systemic treatments in DTC patients.

\section{Management}

The main recommendations regarding the management of BM in DTC included in the most recent guidelines are summarized in Table 2 [32, 48-50].

\section{Radioiodine therapy}

In presence of RAI-avid metastases, RAI therapy is normally used as a first-line treatment in DTC patients [32]. However, although RAI may eradicate small metastases, it is poorly effective in treating larger lesions [12]. Moreover, metastatic patients might show complete or partial lack of RAI uptake, with a significant negative impact on prognosis [50].

In the specific setting of BM, RAI therapy was found to exert favourable effects on survival in patients with RAIavid BM [17] and, as previously underlined, these patients show better survival rates when compared to patients with non-RAI avid BM [13]. According to a recent retrospective study, RAI treatment in combination with one or more non-RAI local or systemic treatments was associated with a significantly increased OS compared with RAI therapy alone [51]. It has also been reported that RAI therapy reduced pain originating from BM [52].

However, when compared to other metastatic sites, RAI therapy resulted less effective in the treatment of BM: for instance, patients with lung metastases showed higher remission rates $(50-74 \%)$ than patients with BM (10-17\%) [3, 53], moreover, more than $20 \%$ of BM do not show any RAI uptake [3, 54].

The efficacy of RAI therapy on BM and its impact on progression-free survival (PFS) and OS are related to several factors. The cumulative activity of RAI resulted significantly associated with improved survival [54]. International guidelines recommend high and repeated activity of at least 3.7-7.4 GBq for lung and bone disease, respectively. However, the potential harms of repeated doses of 


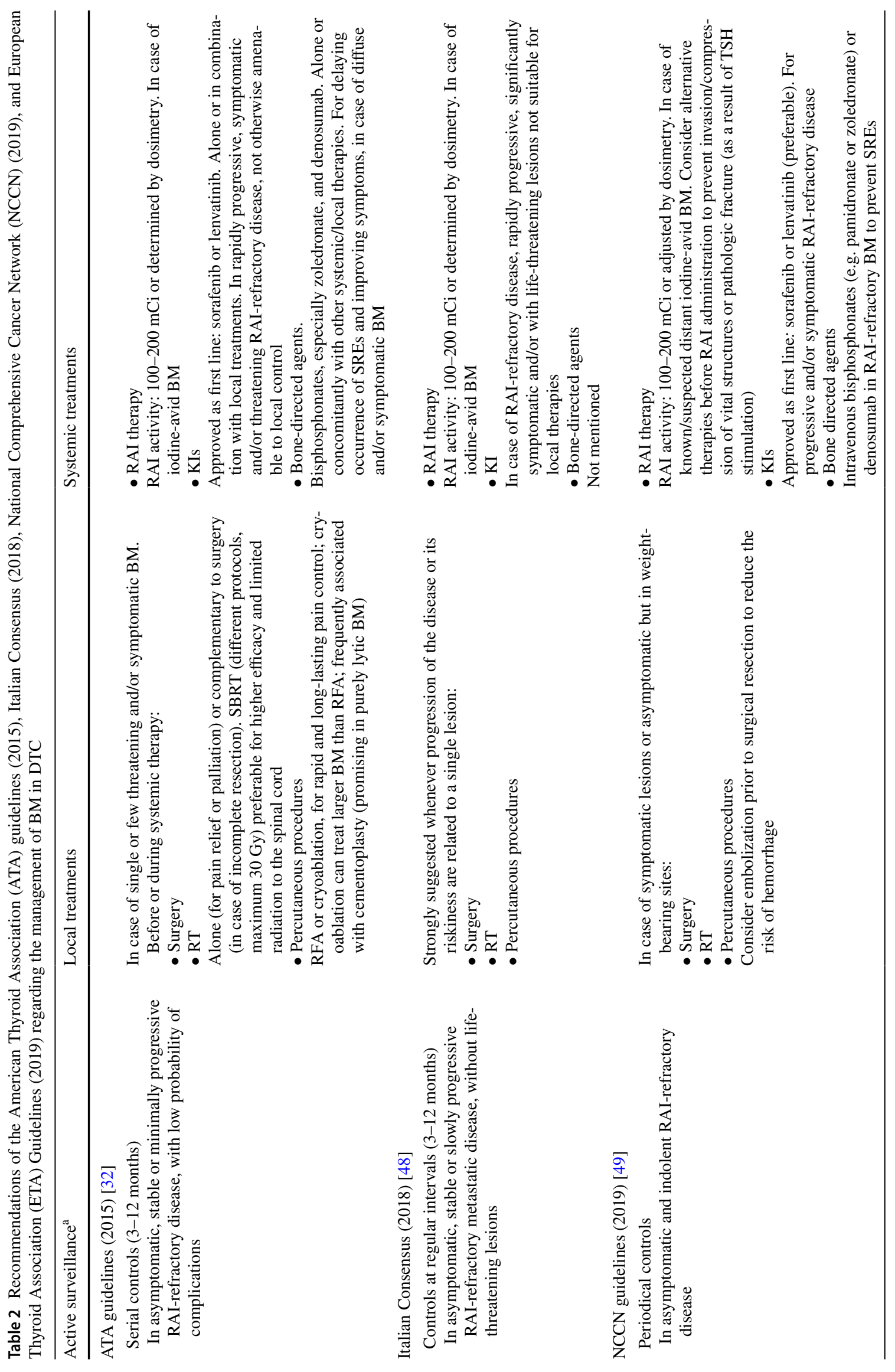




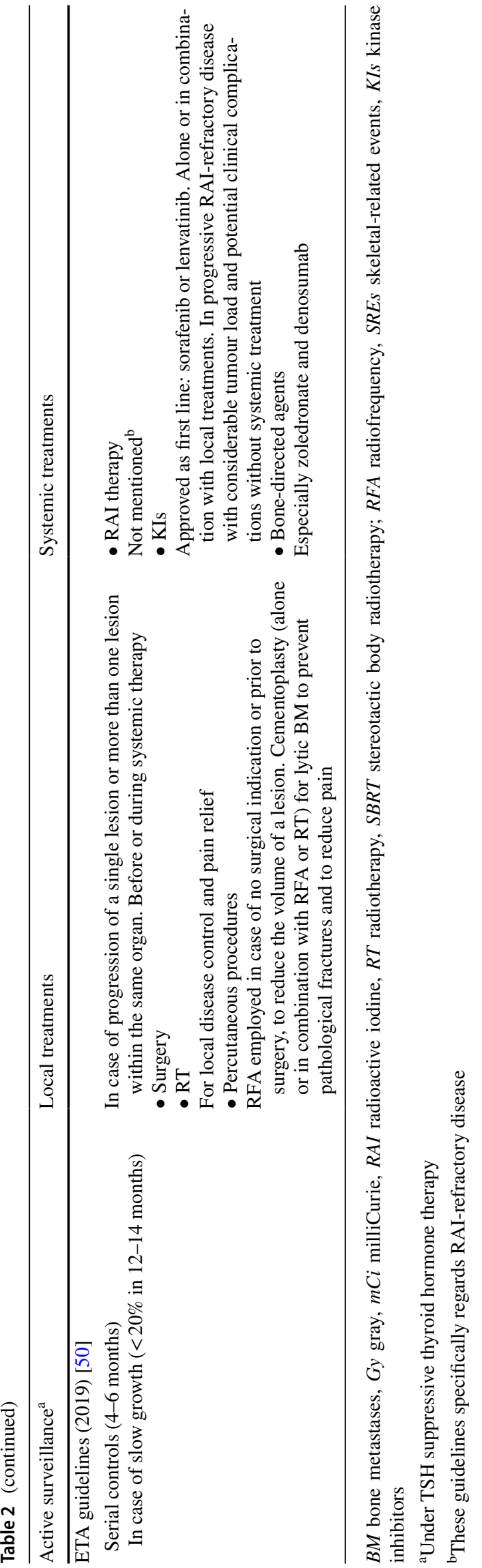

RAI (i.e. bone marrow suppression) should be carefully taken into account and dosimetry, in this setting, can be a useful tool to reduce the risk of long-term toxicity [32].

Dosimetric studies allow to evaluate the absorbed dose to each lesion. The dosimetric approach demonstrated higher efficacy when compared to the empiric approach in locally advanced DTC [55]. Conversely, in the context of metastatic disease, no significant differences were found in terms of OS and PFS comparing empiric versus dosimetric approach, especially in patients with multiple and larger metastases [55-58]. In the specific setting of DTC patients with BM, no controlled studies compared the benefit of empirical RAI administration to a dosimetrically determined dose of RAI therapy.

Both ${ }^{131} \mathrm{I}$ or ${ }^{124} \mathrm{I}$ isotopes can be used to quantify RAI uptake; for this purpose, the use of ${ }^{124}$ I PET/CT seems to be extremely helpful thanks to both the PET images and the longer half-life of ${ }^{124} I[59,60]$. Jentzen et al. reported a low efficacy of RAI therapy for BM even using a dosimetry-guided approach with ${ }^{124} \mathrm{I}$ PET/CT; it was also confirmed the need of higher absorbed doses for BM to obtain a response compared to those reached for lung metastases [61]. However, the use of ${ }^{124} \mathrm{I}$ is hampered by its restricted availability.

RAI refractoriness is defined according to five different scenarios: (1) no RAI uptake is present on a diagnostic ${ }^{131} \mathrm{I}$ WB scan; (2) no RAI uptake is present on a ${ }^{131}$ I WB scan performed several days after RAI therapy; (3) RAI uptake is not present in all tumour foci but only in some of them; (4) disease progression despite RAI uptake; (5) disease progression despite a cumulative RAI activity $>22.2 \mathrm{GBq}$ (600 mCi) [62]. In metastatic patients, ${ }^{18}$ F-FDG PET/ CT should be used as a complementary tool to RAI WB scan to predict $\mathrm{BM}$ response to RAI and to better define RAI-refractory DTC. Patients with ${ }^{18}$ FDG-avid and non RAI-avid distant metastases generally have a rapidly progressive disease. In contrast, patients with RAI-avid and ${ }^{18}$ F-FDG negative lesions have a better prognosis. Patients with both ${ }^{18} \mathrm{~F}-\mathrm{FDG}$ and RAI uptake in the same lesion or in different lesions represent a very heterogeneous group, but their prognosis seems to be similar to the group with only ${ }^{18}$ F-FDG uptake [63] Therefore, ${ }^{18}$ F-FDG PET/CT could help to identify tumours or single lesions with an aggressive behavior that could benefit from other local or systemic therapies different from RAI (Fig. 4) [62].

It is worth remembering that RAI treatment may be contraindicated for large BM at certain sites (e.g. cranium or spine), due to the possible enlargement of the tumour lesions induced by TSH increase either obtained by the administration of rhTSH or after hormone withdrawal, which can lead to compressive symptoms [64]. 


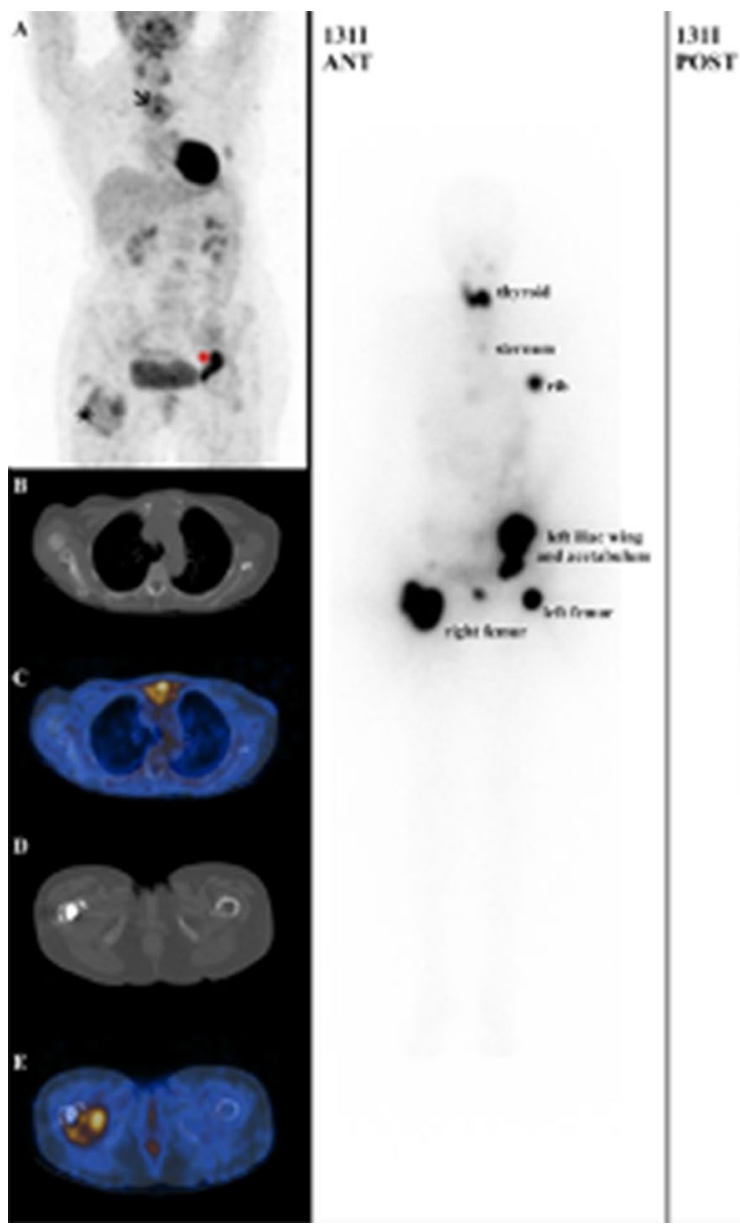

Fig. 4 Case presentation of a 67-year-old female patient with metastatic PTC. (a-e) images show baseline 18F-FDG PET/CT scans. After the diagnosis, she underwent total thyroidectomy (pT3Nx) with a partial resection of the sternum metastasis, and RAI treatment (activity $5.5 \mathrm{GBq}$ ). The 131I whole-body scan (131I ANT and 131I POST) showed RAI uptake in all metastases detected at the baseline 18F-FDG PET/CT, with an heterogenous FDG-avidity (131I+/18FFDG+). A second RAI treatment was not performed for persistent neutropenia; for this reason, the patient was candidate for locoregional therapy (RFA of the left iliac wing and left acetabulum) and she was followed-up with 18F-FDG PET/CT. The first follow-up

\section{Surgery}

Surgery is a possible treatment option for BM, especially for spinal metastasis. Surgical approach is mainly indicated in presence of impending fracture risk, persistent pain, and spinal instability (with or without spinal compression and neurologic injury) [4].

Albeit not always feasible, some authors suggested that complete resection of macroscopically identified bone tumour should be attempted, since this strategy has been associated in some studies with better OS, especially in younger patients with single or few BM. The survival

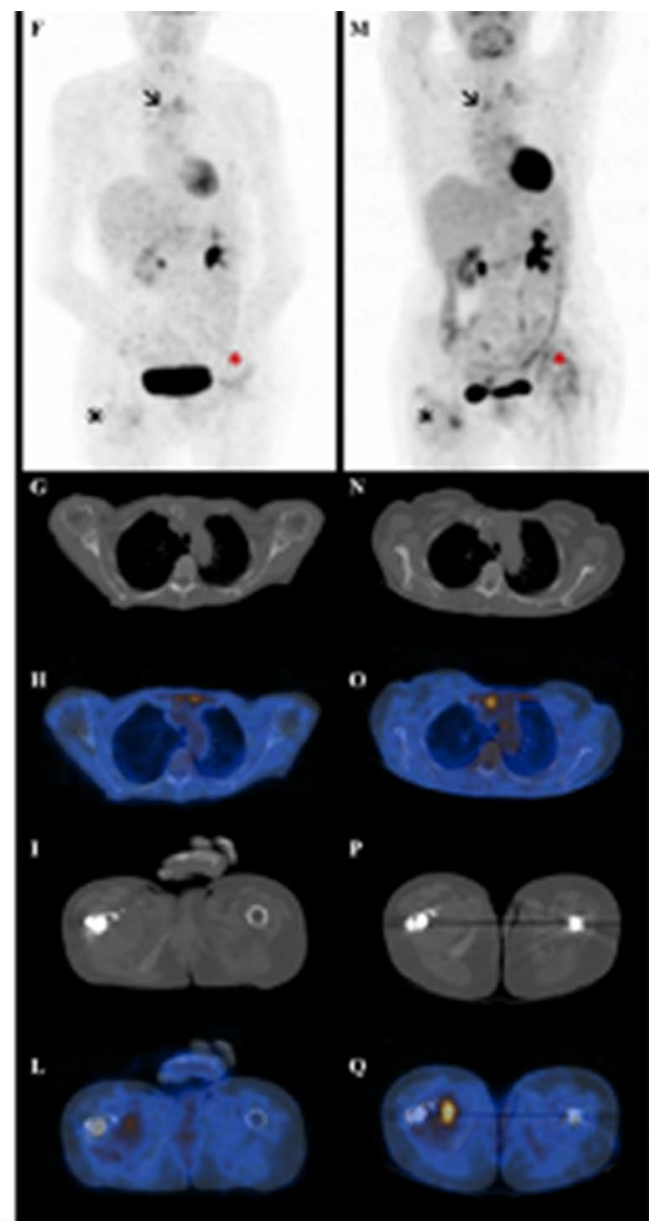

18F-FDG PET/CT scan (f-l) demonstrated a very good metabolic partial response of the left iliac wing and left acetabulum BM (red asterisk), with also a decreased tracer uptake at the right femur level (black asterisk). Despite that, 18F-FDG PET/CT scan performed after 12 months of follow-up $(\mathbf{m}-\mathbf{q})$ showed disease progression, with the appearance of new increased tracer uptake in all the previous sites of disease (sternum, left iliac wing and left acetabulum and right femur). PTC papillary thyroid cancer, $18 F-F D G$ PET/CT $18 \mathrm{~F}$-fluorodeoxyglucose positron emission tomography/computed tomography, RAI radioactive iodine, $R F A$ radiofrequency ablation, $B M$ bone metastases

advantage seems to be evident for both appendicular and spinal BM [54, 65-67].

In contrast, other studies did not find any significant reduction in overall mortality in surgically treated patients $[17,68]$. Nevertheless, total en-bloc spondilectomy (TES) has been associated with lower risk of local recurrence and need for reintervention [68].

When aggressive surgical resection is not feasible (i.e. extensive metastatic disease, comorbidity, advanced age, size of BM), despite the lack of a survival benefit, surgery remains a valuable choice for the palliation of BM-related symptoms or the prevention of pathological fracture and 
spinal cord compression in case of BM in weight-bearing sites [69].

\section{Radiotherapy}

External beam radiation therapy (EBRT) is widely used in clinical practice. It can complement surgery as adjuvant treatment or be used alone, in case of refractory bone pain, for prevention of pathological fractures or in case of spinal compression [70]. Despite the relative radioresistance of DTC [71], EBRT represents an effective and safe treatment approach for non-surgical candidates with symptomatic BM or asymptomatic BM at higher risk of fracture and/or neurological symptoms.

Generally, the onset of the therapeutic effect is not immediate after the end of the radiotherapy course, unless a single dose of $8 \mathrm{~Gy}$ is used. More typical fractionation schemes, however, consist of $20 \mathrm{~Gy}$ in five fractions in 1 week, or $30 \mathrm{~Gy}$ in ten fractions in 2 weeks $[72,73]$.

The development of a more accurate technique called stereotactic ablative radiotherapy or stereotactic body radiotherapy (SABR or SBRT) has changed the treatment paradigm, especially for spinal metastases. It achieves a high level of conformality around the target with a steep dose fall-off, providing higher radiation doses (14-16 Gy in a single fraction) to the target lesions and limiting the dose and the risk of damage to the surrounding critical organs [74]. Thanks to these characteristics, SABR could achieve better results and, if necessary, it allows the reirradiation of previously treated sites.

Few studies investigated the efficacy of SABR in DTC patients with $\mathrm{BM}$; furthermore, SABR protocols differed among them [75-78].

A prospective evaluation of frame-based SABR was performed in thyroid cancer patients (mainly DTC) treated with intensity-modulated radiation therapy (IMRT) in single or multi-fraction schedules (from 16-18 Gy in one fraction to 27-30 Gy in three to five fractions) as primary or adjuvant/ salvage therapy. Local control rates were $88 \%$ at 2 years and $79 \%$ at 3 years, but pain flare was reported by $30 \%$ of patients [75].

A retrospective study showed a 1-year local control rate of $97.5 \%$ and a significant improvement in reported symptoms in a small series of 13 DTC patients with a total of 60 BM (both spinal and non-spinal) treated with Cyberknife (1-10 fractions, with a median dose of $27 \mathrm{~Gy}$ ), a dedicated radiosurgical system consisting of a robotic arm with a linear accelerator and a target tracking system. Most irradiated lesions tended to shrink or decrease in growth rate after SABR [76]. Another retrospective study showed promising results with this technique [77]. Figure 5 is an example of a successful Cyberknife treatment. Conversely, lower rates of local control (67\% at 1 year) were observed in a recent retrospective cohort of 12 patients with a total of 32 spinal metastases treated with Cyberknife [78]. These findings may be mainly explained by the baseline patient characteristics (high rate of extra-spinal metastases, poor performance status [PS]).

In all the previous cited studies, SABR was generally well tolerated and not associated to the onset of myelopathy. However, a significant risk of vertebral compression fractures has been described after this type of treatment, particularly in older subjects, in case of a pre-existing fracture or osteolytic lesions with high tumour burden, high radiation dose and baseline pain. Patients with these risk factors should be carefully evaluated for prophylactic stabilization prior to SABR to avoid this potential complication [79, 80].

Although the use of SABR seems to lead to a significant improvement in PFS and OS in patients with oligometastatic disease from other types of cancer [81], the real impact on the survival rate of DTC patients remains to be established. A recent real-life retrospective evaluation did not show any significant effect of EBRT in reducing the overall mortality of DTC with BM at multivariate analysis [17]. Further studies are needed to select those patients amenable to sophisticated radiotherapy techniques such as SABR.

\section{Percutaneous procedures}

Interventional radiology plays an important role in the management of single or few BM from DTC. It can be a less aggressive alternative to surgery in selected patients (i.e. in case of poor patient PS, or local recurrence at the site of previous surgery), both before or during systemic therapy in case of symptomatic BM at higher risk of local complications. Although patients are usually referred for percutaneous procedures due to their symptomatic status, a more relevant curative role has been hypothesized and need to be further investigated [82].

The available percutaneous techniques can be divided in vascular, ablative and consolidative treatments, which could be applied alone as well as in combination [83]. Published experience in DTC patients is limited and randomized prospective studies comparing the efficacy and tolerability of different procedures are lacking. Their choice in clinical practice is mainly based on local experience, lesion site, and patient preference [32].

Embolization techniques: embolization therapy aims to achieve an extended devascularisation of the tumour tissue through vascular occlusion with different agents, causing ischaemia, and subsequent necrosis. The rational of its use in case of BM from DTC is that these lesions are usually hypervascularised. In selected patients, embolization therapy has been employed in DTC with BM either alone or in combination with other treatment modalities [83]. 


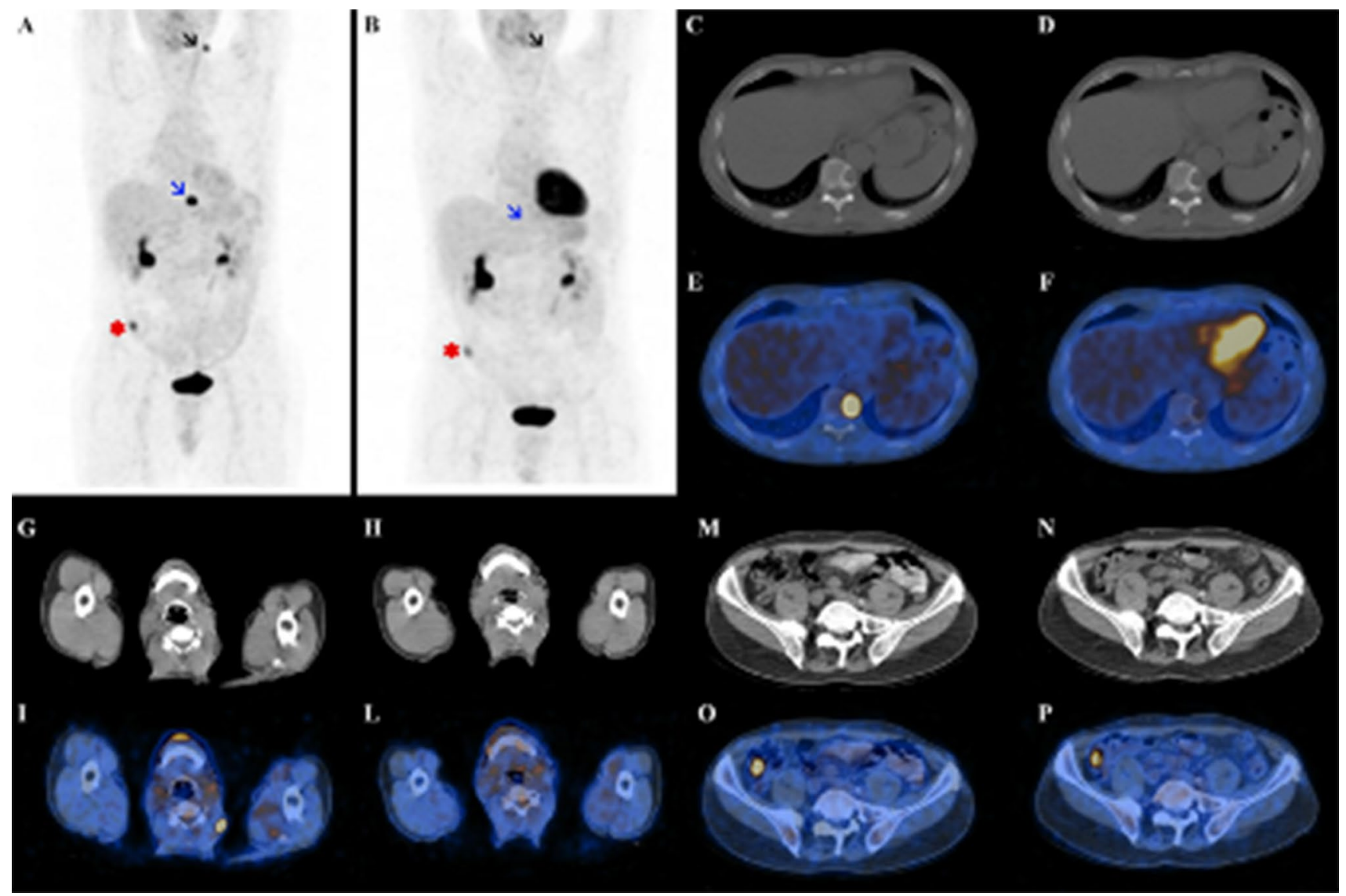

Fig. 5 Case presentation of a 68-year-old male patient with metastatic PTC. He underwent total thyroidectomy (pT3mN1bMx) and two consecutive RAI treatments (cumulative activity $11.1 \mathrm{GBq}$ ). After the second RAI treatment, 18F-FDG PET/CT demonstrated three FDG-avid lesions: a left cervical lymph node (black arrow on a image; see also $\mathbf{g}$ and $\mathbf{i}$ ), a lytic bone lesion in D10 (blue arrow on $\mathbf{a}$ image; see also $\mathbf{c}$ and $\mathbf{e}$ ) and a focal intestinal uptake (asterisk on a image; see also $\mathbf{m}$ and $\mathbf{o}$ ). So, the patient underwent a cervical lymphadenectomy that confirmed the thyroid origin of the lesion, and a Cyberknife radiosurgery of the D10 bone lesion ( $24 \mathrm{~Gy}$ ). The subsequent follow-up 18F-FDG PET/CT scan demonstrated a complete

This treatment does not seem to improve life expectancy, but may achieve remission of symptoms and reduction of tumour burden [84]. The embolization procedure could facilitate subsequent surgical interventions by inducing tumour shrinkage, reducing intraoperative bleeding and allowing a better delimitation between the tumour and the surrounding tissues $[85,86]$.

Better results in terms of duration of symptoms control without tumour progression were observed when this treatment was combined with EBRT or RAI therapy [87].

Ablation techniques: radiofrequency ablation (RFA) and cryoablation (CA) can achieve necrosis of the tumour tissue by an increase or a decrease of intra-tumour temperature, respectively. Their use has been described also in the context of DTC with BM [82, 88]. Another form of thermal ablation metabolic response of the D10 bone lesion (blue arrow on $\mathbf{b}$ image; see also $\mathbf{f}$ ), even if its radiological aspect was unchanged on CT (d); moreover, no further pathological radiotracer uptake was detected in the left cervical region (black arrow on $\mathbf{b}$ image; see also $\mathbf{h}$ and $\mathbf{l}$ ). The focal intestinal uptake was stable (asterisk on $\mathbf{b}$ image; see also $\mathbf{n}$ and $\mathbf{p}$ ) and was diagnosed as an adenomatous polyp at the subsequent polypectomy. The 18F-FDG PET/CT findings were further validated by the concomitant reduction of serum Tg levels. PTC papillary thyroid cancer, $R A I$ radioactive iodine, $18 F-F D G P E T / C T$ 18F-fluorodeoxyglucose positron emission tomography/computed tomography, $\mathrm{Tg}$ thyroglobulin

is microwave ablation (MWA), which uses electromagnetic waves to increase the intra-tumour temperature. When all these techniques are applied to sites exposed to mechanical stresses, a subsequent consolidation with surgical or percutaneous procedures can avoid secondary bone fractures [83].

Ablation techniques have potential advantages compared with surgery and radiation therapy, including reduced morbidity, repeatability, lower procedural cost, short procedural time and the possibility to be performed in an outpatient setting [89]; moreover, they were found to be, either alone or in combination with cementoplasty, effective and safe treatments for painful metastases [87].

Cementoplasty: percutaneous cementoplasty is a minimally invasive procedure which consists in a polymethylmethacrylate (PMMA, also referred to as "bone cement") 
injection into bone segments with structural weakness, obtaining biomechanical stability and pain relief [90, 91]. The best candidates for this procedure are patients suffering from refractory pain due to osteolytic spinal metastases, conversely, cementoplasty is not indicated in purely osteoblastic lesions that, anyway, are rare in DTC. Available studies regarding vertebroplasty in DTC are mostly small series or case reports [91]. Cazzato et al. reported a single-institution experience in percutaneous image-guided treatment of BM from DTC; cementoplasty was performed in $77.5 \%$ of BM and was associated with a good percentage of local tumour control [82]. Vertebroplasty can be combined with other procedures, such as RFA and RAI therapy $[92,93]$.

\section{Kinase inhibitors}

In recent years, KIs have been successfully employed for the treatment of progressive RAI-refractory DTC with distant metastases, included BM [43]. According to the most recent guidelines, systemic treatment should be considered for patients with progressive RAI-refractory disease and considerable tumour burden [32, 48-50].

In a post hoc analysis of a phase III trial, patients with BM treated with lenvatinib showed a PFS benefit in comparison with their non-treated counterpart (median PFS 14.8 vs 2.1 months, HR 0.26) [94].

Conversely, a worse response to treatment and a shorter PFS have been reported in different studies that included patients treated with sorafenib and sunitinib in case of BM [95-98]. Interestingly, BM which had received EBRT before the onset of KI therapy were found to be stable during KI therapy, while non-irradiated BM experienced progression despite a response to KI being observed in extra-bone lesions [95]. Progression of BM while on KI might occur despite maintained benefit at other metastatic sites [99]. These findings suggest the need of a multimodal approach for the management of DTC patients with BM also after initiation of cytostatic therapy, which should be continued with the aim of optimizing systemic disease control.

\section{Antiresorptive treatments}

Acting as potent inhibitors of bone resorption by inducing apoptosis of osteoclasts, bisphosphonates (BPs) have been widely used for preventing or delaying SREs, mainly in patients with breast and prostate cancer [100, 101]. More recently, denosumab, a monoclonal antibody that inhibits osteoclast activity by targeting the RANK ligand, has been successfully employed in these patients, showing a stronger efficacy in delaying SREs when compared to zoledronic acid (ZA) [102].

The effects of bone-directed therapy in DTC patients with $\mathrm{BM}$ have been investigated in a limited number of patients only. In ten DTC patients with BM, administration of pamidronate was associated with reduction of bone pain and improved quality of life [103]. In retrospective evaluations of DTC patients with BM, SREs incidence was significantly lower in ZA-treated patients than in non-treated patients [104, 105]. The use of ZA significantly delayed the onset of the first SRE [104]. A prospective study enrolled 19 DTC patients with BM to receive ZA every 4-5 weeks: a minor occurrence of metastatic spinal cord compression was observed in these patients when compared to 16 non-treated historical controls [106]. More recently, a study investigated the outcome of DTC patients with BM who received only RAI therapy with those who were also treated with non-RAI therapies. In this population, patients who received denosumab showed a better survival than those who did not, even subjects treated with BPs seemed to have slightly improved survival, but statistical significance was not reached [51].

Unexpectedly, the use of BPs or denosumab in DTC patients with BM is still limited in clinical practice. A retrospectively evaluation of the real-life management of $\mathrm{BM}$ in 143 patients with DTC revealed that only $22.4 \%$ of them received anti-resorptive bone-active therapy (ZA in all but one cases), mainly in case of pre-existing SREs [17].

Adverse events (AEs) associated with antiresorptive therapy are generally mild and can be easily managed. During intravenous BPs, acute phase reaction (a flu-like syndrome characterized by fever and arthralgias/myalgias) mainly occurs after the first administration and it is usually self-limiting, while BPs-induced nephrotoxicity is directly related to dose and infusion time [65]. With denosumab, fewer renal AEs and acute-phase responses have been reported, while hypocalcemia seems to occur more frequently. In patients treated with antiresorptive treatment, an adequate vitamin $\mathrm{D}$ and calcium supplementation are essential to prevent hypocalcemia and reach an optimal bone mineral density response, especially in case of hypoparathyroidism. Osteonecrosis of the jaw (ONJ) and atypical femoral fractures are rare, but serious AEs of antiresorptive treatments, the incidence rates of these side effects with ZA, and denosumab do not differ significantly $[107,108]$. Since the risk of ONJ is higher in patients with malignancies and during chemotherapy or head and neck EBRT, a careful dental evaluation prior to initiation of antiresorptive treatments is mandatory in these patients [65].

The potential harms and benefits of concomitant use of antiresorptive treatments and KIs remain to be established, since anti-angiogenic therapies have been associated with the occurrence of ONJ also in absence of antiresorptive treatments in DTC [109]. A study investigating the efficacy of lenvatinib combined with denosumab in the treatment of patients with predominant bone metastatic RAI refractory DTC (LENVOS) is ongoing (NCT03732495). Recently, a retrospective study included 23 patients with BM from 
thyroid cancer (mainly DTC) treated with denosumab, mostly in association with KI therapy: ONJ and severe hypocalcemia occurred in $26 \%$ and $13 \%$ of patients, respectively [110].

The optimal dosing interval for bone-directed therapy is still uncertain. Among breast cancer patients, ZA therapy every 12 week-rather than every 4 week-has been proposed and might be considered an acceptable treatment schedule. Indeed, no difference in terms of SREs occurrence has been observed, while incidence of ONJ and kidney dysfunction resulted lower in the 12-week population, even if statistical significance was not reached [111]. In DTC population, randomized trial data to clarify this issue have not yet been published. Also, the ideal duration of antiresorptive therapy in this population remains controversial.

\section{Conclusion}

In patients with metastatic DTC, BM can be frequently detected and are generally associated with low survival rates. SREs might represent a serious complication of BM, resulting in high morbidity and impaired quality of life. A whole understanding of the molecular mechanisms involved in the development of BM in DTC is still lacking. Several factors were found to predict the natural history of the disease in patients with BM (e.g. age, RAI-avidity, lesion size, time of diagnosis, coexistence of non-bone metastases). A careful multidisciplinary and personalized evaluation is essential to improve the clinical outcome of each patient. BM from DTC can be detected by anatomic imaging (CT and/or MRI) or functional assessment (mainly ${ }^{131}$ I scintigraphy with the added value of SPECT/CT and/or ${ }^{18}$ F-FDG PET/CT). RAI therapy exerts favourable effects on patient survival in case of RAI-avid BM, but it is not curative in case of high volume $\mathrm{BM}$ and in case of RAI-refractory disease. Local treatments (e.g. surgery, radiotherapy including SABR, and percutaneous procedures such as embolization, radiofrequency ablation, cryoablation and cementoplasty) showed good results, alone or in combination with systemic treatment. More recently, KIs have been introduced for the management of patients with progressive RAI-refractory disease and considerable tumour burden, including subjects with BM. The radiological evaluation of response to systemic therapy is challenging: RECIST criteria have several limits in presence of BM. The effects of bone-directed therapy (BPs and denosumab) have been investigated in a limited number of patients only. Future prospective studies focusing on still unsolved issues (e.g. best RAI approach, dose and schedule of BPs, potential role of immunotherapy, optimal sequence of BM treatments, novel techniques of treatment, etc.) are needed to personalize the management of these patients and improve their clinical outcome.
Acknowledgments Open access funding provided by Università degli Studi di Torino within the CRUI-CARE Agreement.

Funding This research did not receive any specific grant from any funding agency in the public, commercial or not-for-profit sector.

\section{Compliance with ethical standards}

Conflict of interest There is no conflict of interest that could be perceived as prejudicing the impartiality of the research reported.

Ethical approval This article does not contain any studies with human participants or animals performed by any of the authors.

Informed consent For this type of study, formal consent is not required.

Open Access This article is licensed under a Creative Commons Attribution 4.0 International License, which permits use, sharing, adaptation, distribution and reproduction in any medium or format, as long as you give appropriate credit to the original author(s) and the source, provide a link to the Creative Commons licence, and indicate if changes were made. The images or other third party material in this article are included in the article's Creative Commons licence, unless indicated otherwise in a credit line to the material. If material is not included in the article's Creative Commons licence and your intended use is not permitted by statutory regulation or exceeds the permitted use, you will need to obtain permission directly from the copyright holder. To view a copy of this licence, visit http://creativecommons.org/licenses/by/4.0/.

\section{References}

1. NIH. National Cancer Institute. SEER (Survelliance, Epidemiology, and End Results Program) cancer statistics. Available from https://seer.cancer.gov/statfacts/html/thyro.html. Accessed 30 Mar 2020

2. Hodak SP, Burman KD (2006) Thyroid carcinoma. metastases to bone. In: Wartofsky L, Van Nostrand D (eds) Thyroid cancer: a comprehensive guide to clinical management, 2nd edn. Humana, New Jersey, pp 497-508

3. Durante C, Haddy N, Baudin E, Leboulleux S, Hartl D, Travagli JP, Caillou B, Ricard M, Lumbroso JD, De Vathaire F, Schlumberger M (2006) Long-term outcome of 444 patients with distant metastases from papillary and follicular thyroid carcinoma: benefits and limits of radioiodine therapy. J Clin Endocrinol Metab 91(8):2892-2899

4. Muresan MM, Olivier P, Leclère J, Sirveaux F, Brunaud L, Klein M, Zarnegar R, Weryha G (2008) Bone metastases from differentiated thyroid carcinoma. Endocr Relat Cancer 15(1):37-49

5. Iñiguez-Ariza NM, Bible KC, Clarke BL (2020) Bone metastases in thyroid cancer. J Bone Oncol 21:100282

6. Pal P, Singh B, Kane S, Chaturvedi P (2018) Bone metastases in follicular carcinoma of thyroid. Indian J Otolaryngol Head Neck Surg 70(1):10-14

7. Osorio M, Moubayed SP, Su H, Urken ML (2017) Systematic review of site distribution of bone metastases in differentiated thyroid cancer. Head Neck 39(4):812-818

8. Farooki A, Leung V, Tala H, Tuttle RM (2012) Skeletal-related events due to bone metastases from differentiated thyroid cancer. J Clin Endocrinol Metab 97(7):2433-2439

9. Choksi P, Papaleontiou M, Guo C, Worden F, Banerjee M, Haymart M (2017) Skeletal complications and mortality in 
thyroid cancer: a population-based study. J Clin Endocrinol Metab 102(4):1254-1260

10. Wexler JA, Sharretts J (2007) Thyroid and bone. Endocrinol Metab Clin North Am 36(3):673-705

11. Cabanillas ME, McFadden DG, Durante C (2016) Thyroid cancer. Lancet 388(10061):2783-2795

12. Robenshtok E, Farooki A, Grewal RK, Tuttle RM (2014) Natural history of small radioiodine-avid bone metastases that have no structural correlate on imaging studies. Endocrine 47(1):266-272

13. Pittas AG, Adler M, Fazzari M, Tickoo S, Rosai J, Larson SM, Robbins RJ (2000) Bone metastases from thyroid carcinoma: clinical characteristics and prognostic variables in one hundred forty-six patients. Thyroid 10(3):261-268

14. Orita Y, Sugitani I, Matsuura M, Ushijima M, Tsukahara K, Fujimoto Y, Kawabata K (2010) Prognostic factors and the therapeutic strategy for patients with bone metastasis from differentiated thyroid carcinoma. Surgery 147(3):424-431

15. Slook O, Levy S, Slutzky-Shraga I, Tsvetov G, Robenshtok E, Shimon I, Benbassat C, Hirsch D (2019) Long-term outcomes and prognostic factors in patients with differentiated thyroid carcinoma and bone metastases. Endocr Pract 25(5):427-437

16. Choi YM, Kim WG, Kwon H, Jeon MJ, Lee JJ, Ryu JS, Hong EG, Kim TY, Shong YK, Kim WB (2016) Early prognostic factors at the time of diagnosis of bone metastasis in patients with bone metastases of differentiated thyroid carcinoma. Eur J Endocrinol 175(3):165-172

17. Mazziotti G, Formenti AM, Panarotto MB, Arvat E, Chiti A, Cuocolo A, Dottorini ME, Durante C, Agate L, Filetti S, Felicetti F, Filice A, Pace L, Pellegrino T, Rodari M, Salvatori M, Tranfaglia C, Versari A, Viola D, Frara S, Berruti A, Giustina A, Giubbini R (2018) Real-life management and outcome of thyroid carcinoma-related bone metastases: results from a nationwide multicenter experience. Endocrine 59(1):90-101

18. Costelloe CM, Rohren EM, Madewell JE, Hamaoka T, Theriault RL, Yu TK, Lewis VO, Ma J, Stafford RJ, Tari AM, Hortobagyi GN, Ueno NT (2009) Imaging bone metastases in breast cancer: techniques and recommendations for diagnosis. Lancet Oncol 10(6):606-614

19. Talbot JN, Paycha F, Balogova S (2011) Diagnosis of bone metastasis: recent comparative studies of imaging modalities. Q J Nucl Med Mol Imaging 55(4):374-410

20. Buhmann Kirchhoff S, Becker C, Duerr HR, Reiser M, BaurMelnyk A (2009) Detection of osseous metastases of the spine: comparison of high resolution multi-detector-CT with MRI. Eur J Radiol 69(3):567-573

21. Jehn CF, Diel IJ, Overkamp F, Kurth A, Schaefer R, Miller K, Lüftner D (2016) Management of metastatic bone disease algorithms for diagnostics and treatment. Anticancer Res 36(6):2631-2637

22. Soliman M, Taunk NK, Simons RE, Osborne JR, Kim MM, Szerlip NJ, Spratt DE (2017) Anatomic and functional imaging in the diagnosis of spine metastases and response assessment after spine radiosurgery. Neurosurg Focus 42(1):E5

23. Stecco A, Trisoglio A, Soligo E, Berardo S, Sukhovei L, Carriero A (2018) Whole-body MRI with diffusion-weighted imaging in bone metastases: a narrative review. Diagnostics (Basel) $8(3): 45$

24. Sakurai Y, Kawai H, Iwano S, Ito S, Ogawa H, Naganawa S (2013) Supplemental value of diffusion-weighted whole-body imaging with background body signal suppression (DWIBS) technique to whole-body magnetic resonance imaging in detection of bone metastases from thyroid cancer. J Med Imaging Radiat Oncol 57(3):297-305

25. Nagamachi S, Wakamatsu H, Kiyohara S, Nishii R, Mizutani Y, Fujita S, Futami S, Arita H, Kuroki M, Nakada H, Uchino N, Tamura S, Kawai K (2011) Comparison of diagnostic and prognostic capabilities of ${ }^{18} \mathrm{~F}$-FDG-PET/CT, ${ }^{131} \mathrm{I}$-scintigraphy, and diffusion-weighted magnetic resonance imaging for postoperative thyroid cancer. Jpn J Radiol 29(6):413-422

26. Mossa-Basha M, Gerszten PC, Myrehaug S, Mayr NA, Yuh WT, Jabehdar Maralani P, Sahgal A, Lo SS (2019) Spinal metastasis: diagnosis, management and follow-up. Br J Radiol 92(1103):20190211

27. Kushchayev SV, Kushchayeva YS, Tella SH, Glushko T, Pacak K, Teytelboym OM (2019) Medullary thyroid carcinoma: an update on imaging. J Thyroid Res 2019:1893047

28. Qiu ZL, Xue YL, Song HJ, Luo QY (2012) Comparison of the diagnostic and prognostic values of 99mTc-MDP-planar bone scintigraphy, 131I-SPECT/CT and 18F-FDG-PET/CT for the detection of bone metastases from differentiated thyroid cancer. Nucl Med Commun 33(12):1232-1242

29. Hassan FU, Mohan HK (2015) Clinical utility of SPECT/CT imaging post-radioiodine therapy: does it enhance patient management in thyroid cancer? Eur Thyroid J 4(4):239-245

30. Wang H, Fu HL, Li JN, Zou RJ, Gu ZH, Wu JC (2009) The role of single-photon emission computed tomography/computed tomography for precise localization of metastases in patients with differentiated thyroid cancer. Clin Imaging 33(1):49-54

31. Oh JR, Byun BH, Hong SP, Chong A, Kim J, Yoo SW, Kang SR, Kim DY, Song HC, Bom HS, Min JJ (2011) Comparison of ${ }^{131}$ I whole-body imaging, ${ }^{131}$ I SPECT/CT, and ${ }^{18}$ F-FDG PET/CT in the detection of metastatic thyroid cancer. Eur J Nucl Med Mol Imaging 38(8): 1459-1468

32. Haugen BR, Alexander EK, Bible KC, Doherty GM, Mandel SJ, Nikiforov YE, Pacini F, Randolph GW, Sawka AM, Schlumberger M, Schuff KG, Sherman SI, Sosa JA, Steward DL, Tuttle RM, Wartofsky L (2016) 2015 American Thyroid Association Management guidelines for adult patients with thyroid nodules and differentiated thyroid cancer: the AMERICAN Thyroid Association guidelines task force on thyroid nodules and differentiated thyroid cancer. Thyroid 26(1):1-133

33. Nascimento C, Borget I, Al Ghuzlan A, Deandreis D, Hartl D, Lumbroso J, Berdelou A, Lepoutre-Lussey C, Mirghani H, Baudin E, Schlumberger M, Leboulleux S (2015) Postoperative fluorine-18-fluorodeoxyglucose positron emission tomography/computed tomography: an important imaging modality in patients with aggressive histology of differentiated thyroid cancer. Thyroid 25(4):437-444

34. Leboulleux S, Schroeder PR, Busaidy NL, Auperin A, Corone C, Jacene HA, Ewertz ME, Bournaud C, Wahl RL, Sherman SI, Ladenson PW, Schlumberger M (2009) Assessment of the incremental value of recombinant thyrotropin stimulation before 2-[18F]-fluoro-2-deoxy-D-glucose positron emission tomography/computed tomography imaging to localize residual differentiated thyroid cancer. J Clin Endocrinol Metab 94(4):1310-1316

35. Chang CY, Gill CM, Joseph Simeone F, Taneja AK, Huang AJ, Torriani M, Bredella MA (2016) Comparison of the diagnostic accuracy of $99 \mathrm{~m}-\mathrm{Tc}-\mathrm{MDP}$ bone scintigraphy and 18 F-FDG PET/CT for the detection of skeletal metastases. Acta Radiol 57(1):58-65

36. Ito $\mathrm{S}$, Kato $\mathrm{K}$, Ikeda M, Iwano $\mathrm{S}$, Makino N, Tadokoro M, Abe S, Nakano S, Nishino M, Ishigaki T, Naganawa S (2007) Comparison of 18F-FDG PET and bone scintigraphy in detection of bone metastases of thyroid cancer. J Nucl Med 48(6):889-895

37. Ota N, Kato K, Iwano S, Ito S, Abe S, Fujita N, Yamashiro K, Yamamoto S, Naganawa S (2014) Comparison of ${ }^{18} \mathrm{~F}$-fluoride $\mathrm{PET} / \mathrm{CT},{ }^{18} \mathrm{~F}-\mathrm{FDG} \mathrm{PET} / \mathrm{CT}$ and bone scintigraphy (planar and SPECT) in detection of bone metastases of differentiated thyroid cancer: a pilot study. Br J Radiol 87(1034):20130444

38. Bhutani M, Turkbey B, Tan E, Korde N, Kwok M, Manasanch EE (2016) Bone marrow abnormalities and early bone lesions in multiple myeloma and its precursor disease: a prospective study 
using functional and morphologic imaging. Leuk Lymphoma 57(5):1114-1121

39. Vaz S, Usmani S, Gnanasegaran G, Van den Wyngaert T (2019) Molecular imaging of bone metastases using bone-targeted tracers. Q J Nucl Med Mol Imaging 63(2):112-128

40. Almeida LS, Araújo MC, Zantut-Wittmann DE, Assumpção LV, Souza TF, Silva CM, Argenton JL, Santos AO, Mengatti J, Ramos CD, Etchebehere EC (2018) Effect of thyroid-stimulating hormone in $68 \mathrm{Ga}$-DOTATATE PET/CT of radioiodinerefractory thyroid carcinoma: a pilot study. Nucl Med Commun 39(5):441-450

41. Parihar AS, Mittal BR, Kumar R, Shukla J, Bhattacharya A (2020) 68Ga-DOTA-RGD2 positron emission tomography/computed tomography in radioiodine-refractory thyroid cancer: prospective comparison of diagnostic accuracy with 18F-FDG positron emission tomography/computed tomography and evaluation toward potential theranostics. Thyroid. https://doi.org/10.1089/ thy.2019.0450(Epub ahead of print)

42. Brose MS, Nutting CM, Jarzab B, Elisei R, Siena S, Bastholt L, de la Fouchardiere C, Pacini F, Paschke R, Shong YK, Sherman SI, Smit JW, Chung J, Kappeler C, Peña C, Molnár I, Schlumberger M, DECISION investigators (2014) Sorafenib in radioactive iodine-refractory, locally advanced or metastatic differentiated thyroid cancer: a randomised, double-blind, phase 3 trial. Lancet 384(9940):319-328

43. Schlumberger M, Tahara M, Wirth LJ, Robinson B, Brose MS, Elisei R, Habra MA, Newbold K, Shah MH, Hoff AO, Gianoukakis AG, Kiyota N, Taylor MH, Kim SB, Krzyzanowska MK, Dutcus CE, de las Heras B, Zhu J, Sherman SI (2015) Lenvatinib versus placebo in radioiodine-refractory thyroid cancer. N Engl J Med. 372(7):621-630

44. Eisenhauer EA, Therasse P, Bogaerts J, Schwartz LH, Sargent D, Ford R, Dancey J, Arbuck S, Gwyther S, Mooney M, Rubinstein L, Shankar L, Dodd L, Kaplan R, Lacombe D, Verweij J (2009) New response evaluation criteria in solid tumours: revised RECIST guideline (version 1.1). Eur J Cancer 45(2):228-247

45. Costelloe CM, Chuang HH, Madewell JE, Ueno NT (2010) Cancer response criteria and bone metastases: RECIST 1.1, MDA and PERCIST. J Cancer 1:80-92

46. Castello A, Lopci E (2019) Response assessment of bone metastatic disease: seeing the forest for the trees RECIST, PERCIST, iRECIST, and PCWG-2. Q J Nucl Med Mol Imaging 63(2):150-158

47. Wang C, Zhang X, Yang X, Li H, Cui R, Guan W, Li X, Zhu Z, Lin Y (2018) PET response assessment in apatinib-treated radioactive iodine-refractory thyroid cancer. Endocr Relat Cancer 25(6):653-663

48. Pacini F, Basolo F, Bellantone R, Boni G, Cannizzaro MA, De Palma M, Durante C, Elisei R, Fadda G, Frasoldati A, Fugazzola L, Guglielmi R, Lombardi CP, Miccoli P, Papini E, Pellegriti G, Pezzullo L, Pontecorvi A, Salvatori M, Seregni E, Vitti P (2018) Italian consensus on diagnosis and treatment of differentiated thyroid cancer: joint statements of six Italian societies. J Endocrinol Invest 41(7):849-876

49. National Comprehensive Cancer network ( $\mathrm{NCCN}$ ) Clinical practice guidelines in oncology. Thyroid carcinoma. Version 1.2019. Available from https://nccn.org. Accessed 18 Mar 2020

50. Fugazzola L, Elisei R, Fuhrer D, Jarzab B, Leboulleux S, Newbold K, Smit J (2019) 2019 European Thyroid Association guidelines for the treatment and follow-up of advanced radioiodinerefractory thyroid cancer. Eur Thyroid J 8(5):227-245

51. Wu D, Gomes Lima CJ, Moreau SL, Kulkarni K, Zeymo A, Burman KD, Wartofsky L, Van Nostrand D (2019) improved survival after multimodal approach with 131I treatment in patients with bone metastases secondary to differentiated thyroid cancer. Thyroid 29(7):971-978
52. Qiu ZL, Song HJ, Xu YH, Luo QY (2011) Efficacy and survival analysis of 131I therapy for bone metastases from differentiated thyroid cancer. J Clin Endocrinol Metab 96(10):3078-3086

53. Schlumberger M, Challeton C, De Vathaire F, Travagli JP, Gardet P, Lumbroso JD, Francese C, Fontaine F, Ricard M, Parmentier C (1996) Radioactive iodine treatment and external radiotherapy for lung and bone metastases from thyroid carcinoma. J Nucl Med 37(4):598-605

54. Bernier MO, Leenhardt L, Hoang C, Aurengo A, Mary JY, Menegaux F, Enkaoua E, Turpin G, Chiras J, Saillant G, Hejblum G (2001) Survival and therapeutic modalities in patients with bone metastases of differentiated thyroid carcinomas. J Clin Endocrinol Metab 86(4):1568-1573

55. Klubo-Gwiezdzinska J, Van Nostrand D, Atkins F, Burman K, Jonklaas J, Mete M, Wartofsky L (2011) Efficacy of dosimetric versus empiric prescribed activity of 131I for therapy of differentiated thyroid cancer. J Clin Endocrinol Metab 96(10):3217-3225

56. Finessi M, Liberini V, Deandreis D (2019) Major limits of dosimetrically determined activities in advanced differentiated thyroid carcinoma. Q J Nucl Med Mol Imaging 63(3):258-266

57. Verburg FA, Flux G, Giovanella L, van Nostrand D, Muylle K, Luster M (2020) Differentiated thyroid cancer patients potentially benefitting from postoperative I-131 therapy: a review of the literature of the past decade. Eur J Nucl Med Mol Imaging 47(1):78-83

58. Deandreis D, Rubino C, Tala H, Leboulleux S, Terroir M, Baudin E, Larson S, Fagin JA, Schlumberger M, Tuttle RM (2017) Comparison of empiric versus whole-body/-blood clearance dosimetry-based approach to radioactive iodine treatment in patients with metastases from differentiated thyroid cancer. J Nucl Med 58(5):717-722

59. Wierts R, Brans B, Havekes B, Kemerink GJ, Halders SG, Schaper NN, Backes WH, Mottaghy FM, Jentzen W (2016) Dose-response relationship in differentiated thyroid cancer patients undergoing radioiodine treatment assessed by means of 124I PET/CT. J Nucl Med 57(7):1027-1032

60. Jentzen W, Hoppenbrouwers J, Van Leeuwen P, Van Der Velden D, Van De Kolk R, Poeppel TD, Nagarajah J, Brandau W, Bockisch A, Rosenbaum-Krumme S (2014) Assessment of lesion response in the initial radioiodine treatment of differentiated thyroid cancer using 124I PET imaging. J Nucl Med 55(11):1759-1765

61. Jentzen W, Verschure F, Van Zon A, Van De Kolk R, Wierts R, Schmitz J, Bockisch A, Binse I (2016) 124I PET assessment of response of bone metastases to initial radioiodine treatment of differentiated thyroid cancer. J Nucl Med 57(10):1499-1504

62. Tuttle RM, Ahuja S, Avram AM, Bernet VJ, Bourguet P, Daniels GH, Dillehay G, Draganescu C, Flux G, Führer D, Giovanella L, Greenspan B, Luster M, Muylle K, Smit JWA, Van Nostrand D, Verburg FA, Hegedüs L (2019) Controversies, Consensus, and Collaboration in the use of 131I therapy in differentiated thyroid cancer: A Joint Statement from the American Thyroid Association, the European Association of Nuclear Medicine, the Society of Nuclear Medicine and Molecular Imaging, and the European Thyroid Association. Thyroid 29(4):461-470

63. Choudhury PS, Gupta M (2018) Differentiated thyroid cancer theranostics: radioiodine and beyond. Br J Radiol 91(1091):20180136

64. Kushchayeva YS, Kushchayev SV, Wexler JA, Carroll NM, Preul MC, Teytelboym OM, Sonntag VK, Van Nostrand D, Burman KD, Boyle LM (2014) Current treatment modalities for spinal metastases secondary to thyroid carcinoma. Thyroid 24(10):1443-1455

65. Wexler JA (2011) Approach to the thyroid cancer patient with bone metastases. J Clin Endocrinol Metab 96(8):2296-2307 
66. Satcher RL, Lin P, Harun N, Feng L, Moon BS, Lewis VO (2012) Surgical management of appendicular skeletal metastases in thyroid carcinoma. Int J Surg Oncol 2012:417086

67. Kato S, Murakami H, Demura S, Fujimaki Y, Yoshioka K, Yokogawa N, Tsuchiya H (2016) The impact of complete surgical resection of spinal metastases on the survival of patients with thyroid cancer. Cancer Med 5(9):2343-2349

68. Demura S, Kawahara N, Murakami H, Abdel-Wanis ME, Kato S, Yoshioka K, Tomita K, Tsuchiya H (2011) Total en bloc spondilectomy for spinal metastasis in thyroid carcinoma. J Neurosurg Spine 14(2):172-176

69. Zhang D, Yin H, Wu Z, Yang X, Liu T, Xiao J (2013) Surgery and survival outcomes of 22 patients with epidural spinal cord compression caused by thyroid tumor spinal metastases. Eur Spine J 22(3):569-576

70. Gerszten PC, Mendel E, Yamada Y (2009) Radiotherapy and radiosurgery for metastatic spine disease: what are the options, indications and outcomes? Spine (Phila Pa 1976) 34(22 Suppl):S78-92

71. Simpson WJ (1990) Radioiodine and radiotherapy in the management of thyroid cancers. Otolaryngol Clin North Am 23(3):509-521

72. Hartsell WF, Scott CB, Bruner DW, Scarantino CW, Ivker RA, Roach M 3rd, Suh JH, Demas WF, Movsas B, Petersen IA, Konski AA, Cleeland CS, Janjan NA, DeSilvio M (2005) Randomized trial of short-versus long-course radiotherapy for palliation of painful bone metastases. J Natl Cancer Inst 97(11):798-804

73. Foro Arnalot P, Fontanals AV, Galcerán JC, Lynd F, Latiesas XS, de Dios NR, Castillejo AR, Bassols ML, Galán JL, Conejo IM, López MA (2008) Randomized clinical trial with two palliative radiotherapy regimens in painful bone metastases: $30 \mathrm{~Gy}$ in 10 fractions compared with $8 \mathrm{~Gy}$ in single fraction. Radiother Oncol 89(2):150-155

74. Gerszten PC, Burton SA, Ozhasglu C, Welch WC (2007) Radiosurgery for spinal metastases: clinical experience in 500 cases from a single institution. Spine (Phila Pa 1976) 32(2):193-199

75. Bernstein MB, Chang EL, Amini B, Pan H, Cabanillas M, Wang XA, Allen PK, Rhines LD, Tatsui C, Li J, Brown PD, Ghia AJ (2016) Spine stereotactic radiosurgery for patients with metastatic thyroid cancer: secondary analysis of phase I/II trials. Thyroid 26(9):1269-1275

76. Ishigaki T, Uruno T, Sugino K, Masaki C, Akaishi J, Hames KY, Suzuki A, Tomoda C, Matsuzu K, Ohkuwa K, Kitagawa W, Nagahama M, Miyazaki S, Ito K (2019) Stereotactic radiotherapy using the CyberKnife is effective for local control of bone metastases from differentiated thyroid cancer. J Radiat Res 60(6):831-836

77. Harada Y, Miyazaki S (2019) Multisession CyberKnife radiosurgery for advanced follicular thyroid cancer. Cureus 11(11):e6159

78. Hariri O, Takayanagi A, Lischalk J, Desai K, Florence TJ, Yazdian P, Chang SD, Vrionis F, Adler JR, Quadri SA, Desai A (2019) Clinical efficacy of frameless stereotactic radiosurgery in the management of spinal metastases from thyroid carcinoma. Spine (Phila Pa 1976) 44(20):E1188-E1195

79. Boehling NS, Grosshans DR, Allen PK, McAleer MF, Burton AW, Azeem S, Rhines LD, Chang EL (2012) Vertebral compression fracture risk after stereotactic body radiotherapy for spinal metastases. J Neurosurg Spine 16(4):379-386

80. Faruqi S, Tseng CL, Whyne C, Alghamdi M, Wilson J, Myrehaug S, Soliman H, Lee Y, Maralani P, Yang V, Fisher C, Sahgal A (2018) Vertebral compression fracture after spine stereotactic body radiation therapy: a review of the pathophysiology and risk factors. Neurosurgery 83(3):314-322
81. Ricardi U, Badellino S, Filippi AR (2016) Clinical applications of stereotactic radiation therapy for oligometastatic cancer patients: a disease-oriented approach. J Radiat Res 57(S1):i58-i68

82. Cazzato RL, Bonichon F, Buy X, Godbert Y, de Figuereido BH, Pointillart V, Palussière J (2015) Over ten years of single-institution experience in percutaneous image-guided treatment of bone metastases from differentiated thyroid cancer. Eur J Surg Oncol 41(9):1247-1255

83. Cazzato RL, Garnon J, Koch G, Shaygi B, Tsoumakidou G, Caudrelier J, Boatta E, Buy X, Palussiere J, Gangi A (2018) Current role of interventional radiology in the management of visceral and bone metastases from thyroid cancer. Gland Surg $7(2): 80-88$

84. De Vries MM, Persoon AC, Jager PL, Gravendeel J, Plukker JT, Sluiter WJ, Links TP (2008) Embolization therapy of bone metastases from epithelial thyroid carcinoma: effect on symptoms and serum thyroglobulin. Thyroid 18(12):1277-1284

85. Smit JW, Vielvoye GJ, Goslings BM (2000) Embolization for vertebral metastases of follicular thyroid carcinoma. J Clin Endocrinol Metab 85(3):989-994

86. Son HY, An SY, Kim EY, Ahn SB, Lee BC (2014) Selective embolization for hypervascular metastasis from differentiated thyroid cancer: a case series. J Med Case Rep 8:405

87. Eustatia-Rutten CF, Romijn JA, Guijt MJ, Vielvoye GJ, van den Berg R, Corssmit EP, Pereira AM, Smit JW (2003) Outcome of palliative embolization of bone metastases in differentiated thyroid carcinoma. J Clin Endocrinol Metab 88(7):3184-3189

88. Barat M, Tselikas L, de Baère T, Gravel G, Yevich S, Delpla A, Magand N, Louvel G, Hadoux J, Berdelou A, Terroir M, Baudin E, Schlumberger M, Leboulleux S, Deschamps F (2019) Thermal-ablation of vertebral metastases prevents adverse events in patients with differentiated thyroid carcinoma. Eur J Radiol 119:108650

89. Goldberg SN, Gazelle GS, Mueller PR (2000) Thermal ablation therapy for focal malignancy: a unified approach to underline principles, techniques, and diagnostic imaging guidance. AJR Am J Roentgenol 174(2):323-331

90. Murphy KJ, Deramond H (2000) Percutaneous vertebroplasty in benign and malignant disease. Neuroimaging Clin N Am 10(3):535-545

91. Kushchayev S, Kushchayeva Y, Theodore N, Preul MC, Clark OH (2010) Percutaneous vertebroplasty for thyroid cancer metastases to the spine. Thyroid 20(5):555-560

92. Orgera G, Krokidis M, Rebonato A, Tipaldi MA, Mascagni L, Rossi M (2019) Thyroid skeletal metastasis: pain management with verteblation. BMJ Support Palliat Care 9(1):e2

93. Song HJ, Wu CG, Xue YL, Xu YH, Qiu ZL, Luo QY (2012) Percutaneous osteoplasty combined with radioiodine therapy as a treatment for bone metastasis developing after differentiated thyroid carcinoma. Clin Nucl Med 37(6):e129-133

94. Habra MA, Song JH, Rietschel P (2015) Outcomes by site of metastasis for patients with radioiodine-refractory differentiated thyroid cancer treated with lenvatinib versus placebo: results from a phase 3, randomized trial. Abstract 55. Presented at 2015 International Thyroid Congress (Orlando, USA)

95. Cabanillas ME, Waguespack SG, Bronstein Y, Williams MD, Feng L, Hernandez M, Lopez A, Sherman SI, Busaidy NL (2010) Treatment with tyrosine kinase inhibitors for patients with differentiated thyroid cancer: the M. D. Anderson experience. J Clin Endocrinol Metab 95(6):2588-2595

96. Hoftijzer H, Heemstra KA, Morreau H, Stokkel MP, Corssmit EP, Gelderblom H, Weijers K, Pereira AM, Huijberts M, Kapiteijn E, Romijn JA, Smit JW (2009) Beneficial effects of sorafenib on tumor progression, but not on radioiodine uptake, in patients with differentiated thyroid carcinoma. Eur J Endocrinol 161(6):923-931 
97. Schneider TC, Abdulrahman RM, Corssmit EP, Morreau H, Smit JW, Kapiteijn E (2012) Long-term analysis of the efficacy and tolerability of sorafenib in advanced radio-iodine refractory differentiated thyroid carcinoma: final results of a phase II trial. Eur J Endocrinol 167(5):643-650

98. Massicotte MH, Brassard M, Claude-Desroches M, Borget I, Bonichon F, Giraudette AL, Do Cao C, Chougnet CN, Leboulleux S, Baudin E, Schlumberger M, de la Fouchardière C (2014) Tyrosine kinase inhibitor treatments in patients with metastatic thyroid carcinomas: a retrospective study of the TUTHYREF network. Eur J Endocrinol 170(4):575-582

99. Haissaguerre M, Leboulleux S, Bonichon F, Borget I, Chougnet CN, Al Ghuzlan A, Hartl DM, Mirghani H, Deandreis D, Baudin E, Schlumberger M (2012) Impact of molecular targeted therapies in patients with bone metastases of differentiated thyroid carcinoma. Abstract 9. Presented at 2012 American Thyroid Association Congress (Quebec City, Canada)

100. Kohno N, Aogi K, Minami H, Nakamura S, Asaga T, Iino Y, Watanabe T, Goessl C, Ohashi Y, Takashima S (2005) Zoledronic acid significantly reduces skeletal complications compared with placebo in Japanese women with bone metastases from breast cancer: a randomized, placebo-controlled trial. J Clin Oncol 23(15):3314-3321

101. Saad F, Chi K, Fleshner N (2004) The role of bisphosphonates in the management of bone metastases in prostate cancer. Can $\mathrm{J}$ Urol 11(5):2376-2382

102. Zheng GZ, Chang B, Lin FX, Xie D, Hu QX, Yu GY, Du SX, Li XD (2017) Meta-analysis comparing denosumab and zoledronic acid for treatment of bone metastases in patients with advanced solid tumours. Eur J Cancer Care 26(6):e12541

103. Vitale G, Fonderico F, Martignetti A, Caraglia M, Ciccarelli A, Nuzzo V, Abbruzzese A, Lupoli G (2001) Pamidronate improves the quality of life and induces clinical remission of bone metastases in patients with thyroid cancer. Br J Cancer 84(12):1586-1590

104. Orita Y, Sugitani I, Toda K, Manabe J, Fujimoto Y (2011) Zoledronic acid in the treatment of bone metastases from differentiated thyroid carcinoma. Thyroid 21(1):31-35
105. Andrade F, Probstner D, Decnop M, Bulzico D, Momesso D, Corbo R, Vaisman M, Vaisman F (2019) The impact of zoledronic acid and radioactive iodine therapy on morbi-mortality of patients with bone metastases of thyroid cancer derived from follicular cells. Eur Thyroid J 8(1):46-55

106. Orita Y, Sugitani I, Takao S, Toda K, Manabe J, Miyata S (2015) Prospective evaluation of zoledronic acid in the treatment of bone metastases from differentiated thyroid carcinoma. Ann Surg Oncol 22(12):4008-4013

107. Chen F, Pu F (2016) Safety of denosumab versus zoledronic acid in patients with bone metastases: a meta-analysis of randomized controlled trials. Oncol Res Treat 39(7-8):453-459

108. Menshawy A, Mattar O, Abdulkarim A, Kasem S, Nasreldin N, Menshawy E, Mohammed S, Abdel-Maboud M, Gadelkarim M, El Ashal GG, Elgebaly AS (2018) Denosumab versus bisphosphonates in patients with advanced cancers-related bone metastasis: systematic review and meta-analysis of randomized controlled trials. Support Care Cancer 26(4):1029-1038

109. Mauceri R, Panzarella V, Morreale I, Campisi G (2019) Medication-related osteonecrosis of the jaw in a cancer patient receiving lenvatinib. Int J Oral Maxillofac Surg 48(12):1530-1532

110. Wassermann J, Mathy E, Lescaille G, Slim M, Buffet C, Saie C, Braik-Djellas Y, Simon JM, Ménégaux F, Tresallet C, Chami L, Lussey-Lepoutre C, Hervé G, Bernier MO, Spano JP, Leenhardt L (2019) Safety of denosumab in patients with refractory differentiated thyroid cancer and advanced medullary thyroid cancer. J Clin Oncol 37(15_suppl):e17578-e17578

111. Cao L, Yong-Jing Yang YJ, Diao JD, Zhang XH, Liu YL, Wang BY, Li ZW, Liu SX (2017) Systematic review and meta-analysis comparing zoledronic acid administered at 12-week and 4 -week intervals in patients with bone metastasis. Oncotarget 8(52):90308-90314

Publisher's Note Springer Nature remains neutral with regard to jurisdictional claims in published maps and institutional affiliations. 